\title{
A POBREZA MULTIDIMENSIONAL EM SALVADOR DIMINUIU? EVIDÊNCIAS SEGUNDO UMA ABORDAGEM ESPACIAL
}

\author{
MULTIDIMENSIONAL POVERTY IN SALVADOR DIMINISHED? \\ EVIDENCE BASED ON A SPATIAL APPROACH
}

\author{
¿LA POBREZA MULTIDIMENSIONAL EN SALVADOR \\ DIMINUIÓ? EVIDENCIAS SEGUN UN ENFOQUE ESPACIAL
}

\section{Eli Izidro dos Santos}

Mestre em Economia Regional e Políticas Públicas pela Universidade Estadual de Santa Cruz (UESC), Brasil / Diretor Administrativo em Teatro Popular de Ilhéus, Brasil.

elyizidro@hotmail.com

\section{Ricardo Candéa Sá Barreto}

Pós-doutor em Economia pela Universidade Federal de Juiz de Fora (UFJF), Brasil / Doutor em Economia Aplicada pela Universidade Federal de Viçosa (UFV), Brasil / Analista de Gestão da Companhia de Água e Esgoto do Ceará (CAGECE), Brasil.

ricardocandea@yahoo.com.br

\section{Ícaro Célio Santos de Carvalho}

Doutorando em Administração de Empresas pela Escola de Administração de Empresas de São Paulo (FGV EAESP), Brasil / Mestre em Economia Regional e Políticas Públicas pela Universidade Estadual de Santa Cruz (UESC), Brasil.

icarocelio@hotmail.com

\section{Contextus}

ISSNe 2178-9258

Organização: Comitê Científico Interinstitucional Editor Científico: Diego de Queiroz Machado

Avaliação: double blind review pelo SEER/OJS Edição de texto e de layout: Carlos Daniel Andrade

Recebido em 22/01/2018

Aceito em 02/06/2018

$2^{\text {a }}$ versão aceita em 15/06/2018

\section{RESUMO}

Este trabalho teve como objetivo analisar a pobreza multidimensional nos bairros de Salvador. No cálculo do Índice de Pobreza (IP), foram consideradas, além da renda, outras variáveis que igualmente representam privações dos cidadãos. Os bairros foram organizados em rankings de pobreza que, por comparação com o IDH, se mostraram consistentes com um estudo espacializado da pobreza na capital baiana, além de evidenciar uma redução de 59,91\% entre 2000 e 2010. Também se encontrou concentração de baixa e de alta pobreza em diversas áreas do município, principalmente na zona norte. A utilização de um modelo econométrico espacial apontou os determinantes da condição de pobreza para os anos de 2000 e 2010, cuja influência foi negativa para a renda média e para a longevidade, enquanto a mortalidade infantil, o analfabetismo e a desigualdade de renda apresentaram influência positiva.

Palavras-chave: Desigualdade Social; Pobreza Multidimensional; Concentração de Pobreza; Índice de Pobreza; Econometria Espacial.

\section{ABSTRACT}

This article aimed to analyze multidimensional poverty in the districts of Salvador. In calculating the Poverty Index (IP), not only income but also other variables were considered that reflect citizens' deprivation. Salvador's districts were organized according to poverty rankings that were, in comparison to the Human Development Index (HDI), consistent with a spatialized study of poverty in the capital of Bahia, in addition to showing a reduction of $59.91 \%$ between 2000 and 2010. Also, low and high levels of poverty were found in several areas of the city, 
especially in the north. Using a spatial econometric model pointed out the poverty determinants for the years 2000 and 2010, whose influence was negative for average income and longevity, whereas infant mortality, illiteracy, and income inequality had a positive influence.

Keywords: Social inequality; Multidimensional poverty; Poverty clusters; Index of Poverty; Spatial econometrics.

\section{RESUMEN}

Este trabajo tuvo como objetivo analizar la pobreza multidimensional en los barrios de Salvador. En el cálculo del Índice de Pobreza (IP), se consideraron, además de la renta, otras variables que también representan privaciones de los ciudadanos. Los barrios se organizaron en rankings de pobreza que, por comparación con el IDH, se mostraron consistentes con un estudio espacializado de la pobreza en la capital bahiana, además de evidenciar una reducción del 59,91\% entre 2000 y 2010. También se encontró concentración de baja y de alta pobreza en diversas áreas del municipio, principalmente en la zona norte. La utilización de un modelo econométrico espacial apuntó los determinantes de la condición de pobreza para los años 2000 y 2010, cuya influencia fue negativa para el ingreso promedio y para la longevidad, mientras que la mortalidad infantil, el analfabetismo y la desigualdad de ingresos presentaron una influencia positiva.

Palabras-clave: Desigualdad social; Pobreza multidimensional; Concentración de pobreza; Índice de Pobreza; Econometría espacial.

\section{INTRODUÇÃO}

As desigualdades econômicas e sociais exercem profundos impactos no bem-estar da sociedade como um todo, a exemplo da pobreza, muitas vezes tratada não apenas como socialmente custosa, mas também como moralmente condenável. Há custos para o poder político relacionados à governança que podem acabar interpretados como sinais de clientelismo. Essa problemática torna-se objeto indispensável de pesquisas, principalmente em países emergentes como o Brasil (PECI; NERI, 2017).

O presente artigo tem como foco o comportamento espacial da pobreza multidimensional, investigando evidências de sua concentração em bairros do município de Salvador. Procurou-se responder às seguintes questões: a) além da renda, quais elementos explicam a situação de pobreza? b) Como a pobreza está dispersa pelos bairros da cidade? Este trabalho se pretende inovador na medida em que amplia as dimensões empíricas da pobreza e utiliza uma escala marcada por maior escassez de informações: os bairros.

Um estudo sobre Salvador justifica-se pelo fato de ser a maior cidade da Bahia em termos populacionais e em arrecadação tributária, mas também apresentar uma série de problemas sociais, ligados principalmente à disparidade de renda e à violência. A capital baiana é apontada como uma das principais capitais brasileiras nesses aspectos. Destaca-se também a abrangência que este tipo de estudo vem tomando nos últimos tempos, alinhado com importantes mudanças a serem adotadas para as políticas públicas obterem maior êxito. Com o intuito de aliviar ou combater as agruras causadas pela pobreza, ressalta-se a necessidade de não atrelar o tema apenas à renda, como tradicionalmente se faz, pois existem outros fatores 
que interferem igualmente sobre a dificuldade (CARVALHO; PEREIRA, 2015).

Esta pesquisa ampara-se na conclusão de Rothwell e Massey (2015) de que nascer em bairros pobres tem efeito negativo no futuro dos indivíduos, pois as condições estabelecidas nos primeiros anos de vida podem impactar no desenvolvimento social do cidadão. A falta de acesso à educação de qualidade, a violência, as desordens sociais, dentre outros fatores, podem retardar a ascensão social.

Diante desse quadro, este estudo teve como objetivo desenvolver uma análise espacial da pobreza multidimensional dos bairros de Salvador para 2000 e 2010. Mais especificamente, buscou-se: (a) mensurar a pobreza nos bairros de Salvador, com base no Índice de Pobreza (IP); (b) analisar espacialmente a pobreza em Salvador; (c) apontar os bairros do município com maior e menor concentração de pobreza; (d) verificar quais variáveis são determinantes da pobreza nos bairros de Salvador nos períodos; e, por fim, (e) identificar o comportamento da pobreza multidimensional nos bairros da capital baiana.

Além desta primeira seção, o artigo está dividido em mais quatro. A segunda seção apresenta a revisão de literatura, que destaca o referencial teórico utilizado para embasar a análise acerca da pobreza. A terceira expõe a metodologia utilizada. A quarta traz as discussões e análises dos resultados encontrados, bem como a espacialização da pobreza nos bairros de Salvador. A quinta seção apresenta as considerações finais do trabalho.

\section{REVISÃO DE LITERATURA}

Sen (2000) considera os relacionamentos existentes numa sociedade como "funcionamentos" e pressupõe como essencial analisar as capacidades dos indivíduos de participarem de tais funcionamentos. Obviamente, essa é uma discussão que ainda terá muitos desdobramentos, podendo seguir uma série de percursos de acordo com seus funcionamentos e capacidades. Vale ressaltar, entretanto, que não existem pesquisas de ampla representatividade, desenhadas especificamente para implementar essa abordagem. Além disso, o estudo pode ser concentrado de duas maneiras: a primeira sob a ótica econômica, que utiliza como base somente a renda; e a segunda sob uma perspectiva que incorpora outras variáveis, não econômicas, de que o cidadão se priva igualmente (SEN, 2000).

Entretanto, assumir que a pobreza não se limita à renda não é suficiente para alcançar resultados efetivos, pois caso não se conheçam de forma clara o objeto de análise e seu 
comportamento, tornam-se extremamente limitadas as tentativas de elaborar e avaliar as políticas voltadas para o combate e, principalmente, de entender a realidade de forma ampla e consistente o suficiente para intervir de forma positiva e duradoura. Assim, por ser um fenômeno complexo, o estudo da pobreza necessita de uma análise envolvendo não só a renda dos indivíduos, mas também outros aspectos e variáveis que impedem um desenvolvimento digno das pessoas, como, por exemplo, más condições de saúde, analfabetismo, falta de moradia digna, falta de participação social, violência, dentre outros.

Contudo, Sen (1999) não descarta o entendimento de que a baixa renda seja uma das maiores causas da pobreza, haja vista sua falta poder ser a principal causa para a privação de capacidades de uma pessoa. Porém, mesmo diante desse entendimento, Sen aponta aspectos que favorecem a abordagem das capacidades em relação à adoção de um padrão de renda para avaliar a pobreza. Em princípio, ele defende que a pobreza pode ser identificada em termos de privação de capacidades, visto esta abordagem se concentrar em privações "intrinsecamente" importantes, diferentemente da baixa renda, que é apenas "instrumentalmente" significante. Outro aspecto é que a renda não é o único instrumento a gerar capacidades, havendo diversos outros fatores que influenciam a privação de capacidades e, portanto, a "pobreza real”. Há ainda o fato de o impacto da renda nas capacidades ser contingente e condicional: a relação instrumental entre baixa renda e baixa capacidade varia entre comunidades distintas, mesmo entre diferentes famílias e indivíduos (LIMA, 2005).

Nesse sentido, esta abordagem é mais abrangente que a abordagem das necessidades básicas, pois considera o acesso dos indivíduos à educação, saúde, infraestrutura (acesso aos bens públicos em geral), além da possibilidade de os indivíduos exercerem sua cidadania e sua representatividade social. Assim, um indicador de pobreza com tais características pode ser considerado subjetivo por considerar o sentimento de pobreza percebido pelos indivíduos, tendendo a avaliar a situação dos cidadãos numa sociedade específica. O Programa das Nações Unidas para o Desenvolvimento (PNUD), por exemplo, usa esse arcabouço como base conceitual e metodológica em seus estudos sobre a pobreza.

No entanto, ainda não há consenso entre os autores, principalmente sobre as linhas de pobreza a serem utilizadas nas pesquisas. E, quando se trata de estudos multidimensionais, essa tarefa se torna ainda mais difícil, pois a escolha das dimensões a serem objeto do estudo e das variáveis a serem utilizadas depende do objetivo do trabalho e do conceito de pobreza utilizado pelo pesquisador (AMARAL; CAMPOS; LIMA, 2016; ROCHA, 2005; HOFFMANN, 2006; KAGEYAMA; HOFFMANN, 2006; 2005). 
Para Lacerda (2009), a grande dificuldade é encontrar um bom indicador, capaz de incorporar o lado multidimensional da pobreza. A autora destaca que, diferentemente do que acontece com os estudos sob o prisma unidimensional, ainda não existe, nas abordagens multidimensionais, um conjunto de medidas estabelecidas e consolidadas. Esse fato ilustra bem a importância da utilização do Índice de Pobreza, utilizado neste trabalho, que engloba no seu arcabouço a renda, a educação, a saúde e habitação/saneamento. De acordo com Ávila (2013), apesar de utilizar dados quantitativos, esse índice foca a qualidade de vida dos indivíduos, não se restringindo apenas à quantificação monetária da pobreza. O IP é inspirado no Índice de Pobreza Humano (IPH) ${ }^{1}$, que foi utilizado no Relatório de Desenvolvimento Humano da PNUD, a partir de 1997, com o objetivo específico de medir a pobreza, utilizando as mesmas variáveis do Índice de Desenvolvimento Humano (IDH), entretanto, com foco nos mais pobres, adotando uma perspectiva das privações do indivíduo. Tem o intuito de medir o tamanho do déficit, utilizando as mesmas dimensões fundamentais consideradas pelo IDH. Nesse sentido, ele é mais uma medida de vulnerabilidade do que propriamente de pobreza. Contudo, existe um consenso entre os estudiosos da pobreza sobre a imprecisão de sua medida (ÁVILA, 2013; LACERDA, 2009). Mas, por outro lado, não há consenso quanto à natureza dessa imprecisão e quanto ao método de apreendê-la. Mesmo entre aqueles que utilizam uma linha de pobreza monetária, há uma preocupação com relação à imprecisão dessa medida, porém a imprecisão é atribuída muito mais à falta de informação do que à natureza do fenômeno estudado. Como apontado por Silva e Barros (2006), sobre a importância de indicadores escalares de pobreza multidimensional, não existe uma forma única para sua construção. A cada passo do processo de construção surgem dilemas como: quais as dimensões mais relevantes? Quais devem ser as variáveis adotadas e seus pesos? Qual deve ser o método de agregação das dimensões de pobreza?

Segundo Espósito e Chiappero-Martinetti (2008), os trabalhos sobre pobreza multidimensional podem ser agrupados em três categorias: i) aqueles que constroem índices de pobreza multidimensionais (FOSTER; GREER; THORBECKE, 1984; FOSTER, 2010; TSUI, 2002; BOURGUIGNON; CHAKRAVARTY, 2002; BIBI, 2005; BOSSERT; CHAKRAVARTY; D’AMBROSIO, 2009); ii) aqueles que propõem critérios de ordenação

\footnotetext{
${ }^{1} \mathrm{O}$ IPH foi construído considerando três indicadores: a) percentual de indivíduos suscetíveis de morrer antes dos 40 anos de idade; b) quantidade de adultos analfabetos; e c) serviços ofertados pelo conjunto da economia. Este último indicador é formado por três variáveis: percentual de pessoas que não têm acesso à água potável, percentual de indivíduos sem acesso aos serviços de saúde e percentual de crianças abaixo dos cinco anos de idade que sofrem de desnutrição. Esse índice foi, em 1998, dividido em dois: o IPH-1, para países em desenvolvimento, e o IPH-2, para países desenvolvidos, de forma a refletir melhor as diferentes condições existentes entre os dois grupos de países (ÁVILA, 2013; LACERDA, 2009; PNUD; 1997).
} 
para a pobreza multidimensional (FOSTER; SHORROCKS, 1988a; 1988b; DUCLOS; SAHN; YOUNGER, 2006; ALKIRE; FOSTER, 2009; BOURGUIGNON; CHAKRAVARTY, 2002); e iii) aqueles que fazem uma análise multidimensional da pobreza baseada no uso de técnicas estatísticas multivariadas (KRISHNAKUMAR, 2005; KAKWANI; SILBER, 2008; ASSELIN, 2002).

Porém, independentemente da linha teórica básica, os pesquisadores que calculam um índice composto de pobreza geralmente buscam reduzir o grau de aleatoriedade na sua determinação, escolhendo medidas de pobreza que satisfaçam alguns postulados como foco, monotonicidade, princípio da população, simetria, decomposabilidade do subgrupo, continuidade, princípio da transferência e pobreza não decrescente sobre aumento da correlação de troca. Ou seja, eles constroem índices de pobreza que requerem uma série de características básicas para que ela possa ser determinada. Destacam-se, nessa linha, Foster, Greer e Thorbecke (1984), Foster (2010), Tsui (2002), Bourguignon e Chakravarty (2003), Alkire e Foster (2009), Bibi (2005) e Bossert, Chakravarty e D’Ambrosio (2009).

No entanto, apesar das mais diversas linhas de pensamento e das várias limitações desse tipo de metodologia, ela se mostra analiticamente aceitável, pois, além de medir a pobreza, busca entendê-la, considerando dimensões mais ligadas à qualidade de vida. Ao interpretar esses índices, possibilita propor e elaborar políticas públicas capazes de atender, de fato, às necessidades dos indivíduos, revelando-se bem mais eficaz que os métodos que utilizam exclusivamente a dimensão renda (ÁVILA, 2013; LACERDA, 2009; SANTOS; CARVALHO; BARRETO, 2017).

\section{METODOLOGIA}

\section{1 Índice de Pobreza}

A metodologia deste trabalho guiou-se por técnicas de distribuição espacial, tendo por base Ávila (2013), cujo índice de pobreza, por sua vez, se fundamenta no Índice de Pobreza Humana (IPH) criado por Anand e Sen (1997). Também fazem parte desse arcabouço a Análise Exploratória de Dados Espaciais (AEDE) e o Índice de Moran Global e Local, instrumentos que possibilitaram espacializar a pobreza e a desigualdade sob uma ótica multidimensional. Além disso, a análise econométrica espacial foi empregada com o objetivo de identificar os 
determinantes da pobreza em Salvador, tendo o IP como variável dependente.

Assim, foi estabelecida uma série de procedimentos para satisfazer e especificar os critérios metodológicos necessários para cumprir tais requisitos. Com base na revisão, descreve-se um IP composto de quatro dimensões: condições de habitação e saneamento, educação, saúde e renda. Foram selecionados indicadores dentro das dimensões desejáveis, bem como os mais viáveis, em função das restrições existentes de dados estatísticos, principalmente, para escalas menores, como bairros.

Nesse sentido, após a coleta dos dados, foi feito o cálculo do IP, tendo como referência as dimensões escolhidas (Quadro 1). Inicialmente, elaborou-se uma tabela com os indicadores de privações para cada um dos bairros, para que, na sequência, pudessem ser feitos os cálculos dos referidos índices. Posteriormente, foi organizado o ranking de pobreza dos bairros soteropolitanos para cada um dos índices calculados.

Quadro 1 - Dimensões e varáveis que compõem o IP

\begin{tabular}{|l|l|l|}
\hline Dimensões (D) & Privações (P) & Referencial conceitual \\
\hline $\begin{array}{l}\text { Habitação e } \\
\text { saneamento } \\
\text { (HS) }\end{array}$ & $\begin{array}{l}\text { 5 ou mais moradores por domicílio (PNUD, } \\
\text { 2014) } \\
\text { Sem paredes adequadas (PNUD, 2014) } \\
\text { Sem coleta de lixo (PNUD, 2014) } \\
\text { Sem energia elétrica (PNUD, 2014) } \\
\text { Sem tratamento de esgoto (PNUD, 2014) } \\
\text { Sem água potável (PNUD, 2014) }\end{array}$ & $\begin{array}{l}\text { ÁVILA (2013), SANTOS, M. } \\
\text { (2014), ALLARDT (1993), } \\
\text { CUMMINS (1996), URA et al. } \\
\text { (2012). }\end{array}$ \\
\hline $\begin{array}{l}\text { Educação (E) } \\
\text { Sem instrução (PNUD, 2014) }\end{array}$ & $\begin{array}{l}\text { ÁVILA (2013), SANTOS, M. } \\
\text { (2014), STIGLITZ, SEN, } \\
\text { FITOUSSI (2009), ALLARDT } \\
\text { (1993), CUMMINS (1996), URA et } \\
\text { al. (2012) }\end{array}$ \\
\hline Saúde (S) & $\begin{array}{l}\text { ÁVILA (2013), SANTOS, M. } \\
\text { (2014), STIGLITZ, SEN, } \\
\text { (PNUD, 2014). }\end{array}$ & $\begin{array}{l}\text { FITOUSSI (2009), ALLARDT } \\
\text { (1993). }\end{array}$ \\
\hline Renda (R) & $\begin{array}{l}\text { Até 1/2 salário-mínimo (SM) ou sem rendimento } \\
\text { (PNUD, 2014). }\end{array}$ & $\begin{array}{l}\text { ÁVILA (2013), SANTOS, M. } \\
\text { (2014), STIGLITZ, SEN, } \\
\text { FITOUSSI (2009), ALLARDT } \\
\text { (1993), CUMMINS (1996), URA et } \\
\text { al. (2012). }\end{array}$ \\
\hline
\end{tabular}

Fonte: elaboração própria.

Assim, foi feita uma análise comparativa dos rankings de pobreza, buscando verificar sua consistência como forma de justificar sua utilização na análise espacial. Para verificar tal consistência dos índices, foi utilizado como base o ranking do IDH para os bairros de Salvador para 2000 e 2010, disponibilizado pela PNUD (2014). 
Destarte, seguindo o arcabouço metodológico, o Índice de Pobreza é apresentado da seguinte forma:

$$
D_{i}=\frac{1}{n}\left(\sum P_{i j}\right)
$$

Em que $D_{i}=$ dimensão a ser calculada; $P_{i j}=$ privação que compõe a variável derivada; $i=$ número que indica a dimensão a ser calculada $(i=1, \ldots, 4) ; j=$ número da privação que compõe a dimensão a ser calculada $(j=1, \ldots, 6)$; e $n=$ quantidade de privações que compõem a dimensão.

Dessa forma, aplicando-se a média ponderada às dimensões $\left(D_{i}\right)$ e reescrevendo-as, têm-se $H S=D_{1}, E=D_{2}, S=D_{3}, C=R_{4}$. Logo, o Índice de Pobreza assume a seguinte expressão:

$$
I P=\left\{\left(\frac{1}{n}\right) \times\left[D_{1}^{a}+D_{2}^{a}+D_{3}^{a}+D_{4}^{a}\right]\right\}^{\frac{1}{a}}
$$

Ou seja: $D=D_{i} ; i=1, \ldots, \mathrm{n}$. Desse modo, na fórmula geral, tem-se:

$$
I P=\left[\left(\sum \frac{\left(D_{i}^{\alpha}\right)}{n}\right)\right]^{\frac{1}{\alpha}}
$$

Em que $n=$ quantidade de dimensões que compõem o índice; e $\alpha=$ fator de ponderação do peso das dimensões que compõem o índice.

Tem-se, dessa forma, os três índices utilizados neste trabalho, assim apresentados:

$$
\begin{aligned}
& I P_{1}=\left\{\left(\frac{1}{n}\right) \times\left[H S^{\alpha}+S^{\alpha}+R^{\alpha}\right]\right\}^{\frac{1}{\alpha}} \\
& \alpha=\mathrm{n}=4 \\
& I P_{2}=\left\{\left(\frac{1}{n}\right) \times\left[H S^{\alpha}+S^{\alpha}+R^{\alpha}\right]\right\}^{\frac{1}{\alpha}} \\
& \alpha=\mathrm{n}=3 \\
& I P_{3}=\left\{\left(\frac{1}{n}\right) \times\left[R^{\alpha}\right]\right\}^{\frac{1}{\alpha}}
\end{aligned}
$$




$$
\begin{aligned}
& \alpha=\mathrm{n}=1 \\
& \text { E, finalmente, tem-se: }
\end{aligned}
$$

$$
\begin{aligned}
& D_{i}=\frac{1}{n\left(\sum P_{i j}\right)} \\
& \mathrm{n}=6 \text { para HS, e } \mathrm{n}=1 \text { para E, S e R }
\end{aligned}
$$

Nessa lógica, procedeu-se ao cálculo dos índices de pobreza ${ }^{2}$ e posteriormente foi feita a análise comparativa dos rankings dos bairros, buscando verificar a consistência dos índices calculados em comparação com o IDH dos bairros de Salvador.

Outro passo importante foi a realização da análise espacial, tendo sido definida, primeiramente, para sua implementação, a matriz de pesos espaciais (W), que representa certa estrutura espacial, na qual uma determinada interação socioeconômica entre os agentes é esperada, sendo, conforme Almeida et al. (2008), a forma de expressar um determinado arranjo espacial das interações resultantes do fenômeno a ser estudado, como primeiro passo para a implementação da Análise Exploratória de Dados Espaciais (AEDE). No entanto, tendo em vista a existência de autocorrelação espacial, foi aplicado a estatística I de Moran Global ${ }^{3}$, pois, segundo Almeida (2012), é a maneira mais aceitável de identificá-la e testá-la. Contudo, quando se lida com um grande número de dados, há sempre a ocorrência de dependência espacial, assim, foi utilizada a estatística I de Moran Local, que permite a identificação de clusters espaciais, em que a comparação é feita não entre bairros, mas entre os indicadores locais e seus vizinhos, verificando, desta forma, se há ou não padrões de concentrações locais.

Segundo Almeida et al. (2008) o objetivo central desse método é descrever a distribuição espacial, os padrões de associação espacial, os possíveis clusters espaciais, verificar a existência de diferentes regimes espaciais ou outras formas de instabilidade espacial (não estacionariedade) e identificar observações espaciais atípicas, ou seja, os outliers. Os autores salientam que, para a implementação da AEDE, faz-se necessário definir, primeiramente, uma

\footnotetext{
${ }^{2}$ Este é um índice cujo valor varia de 0 a 100. Logo, o valor final do IP indica qual a proporção de pobres no bairro. Dessa forma, quanto mais próximo de 100 for o resultado, maior será o grau de pobreza. Os bairros com índice de 0 a $14,99 \%$ são considerados de baixa pobreza; aqueles com índice de $15 \%$ a $29,99 \%$ são classificados como de média; os que galgam índice de $30 \%$ a $49,99 \%$ são tidos como de alta pobreza; e aqueles com índice de $50 \%$ ou mais se classificam com grau de pobreza muito alto. Salienta-se que este foi um arranjo, praticado para este estudo, na metodologia original proposta por Ávila (2013), devido a uma menor escala dos bairros, em relação aos municípios ou estados, por exemplo.

${ }^{3}$ Consiste em uma medida de autocorrelação espacial que aponta para a existência ou não de agrupamentos espaciais para uma dada variável, isto é, para a presença de índices de pobreza com valores similares entre vizinhos, segundo um determinado indicador de interesse (ALMEIDA et al., 2008).
} 
matriz de pesos espaciais (W). Destacam, ainda, que a escolha da matriz de pesos espaciais é muito importante em uma AEDE, pois os resultados da análise são sensíveis a tal seleção. Logo, diante da ideia contida na matriz de vizinhança, há existência de uma maior interação espacial entre os vizinhos mais próximos do que com os mais distantes. Ávila (2013) afirma que o resultado desta interação esperada é que o índice de pobreza de determinado bairro influencie e seja influenciado pelos índices dos bairros com os quais faz fronteira e que essa influência vai diminuindo na medida em que a distância interbairros aumenta.

Dessa forma, inicialmente foram definidos a matriz e o nível de contiguidade para, posteriormente, proceder-se à análise tendo como referência a elaboração dos mapas. Assim, foi feito o teste de autocorrelação espacial ou I de Moran, que indicou que o uso da matriz de distâncias euclidiana, pela média do centroide, seria a configuração mais indicada, pois apresentou o maior nível de significância estatística, para ambos os períodos e índices, o que está coerente com os preceitos metodológicos (ANSELIN, 1988; ALMEIDA, 2012). Outras matrizes espaciais foram testadas com o objetivo de aumentar o rigor desse teste ${ }^{4}$ e identificar qual delas capta a maior autocorrelação sobre o objeto de estudo, evidenciando que a pobreza de um bairro depende, pelo menos em parte, das características de seus vizinhos.

\subsection{Modelo econométrico}

De acordo com a disponibilidade dos dados e a metodologia para mensurar o efeito dos determinantes da pobreza, a composição do modelo utilizado e a estimação foram feitas com base nos trabalhos de Giovanetti e Raiher (2015) e Rothwell e Massey (2015), resultando no seguinte:

$$
\begin{aligned}
& \ln \left(I P_{1}\right)=\beta_{0}+\rho W_{1} \ln \left(I P_{1}\right)+\beta_{1} \ln (R)+\beta_{2} \ln (E)+\beta_{3} \ln (S)+\beta_{4} \ln (L) \\
& u=\lambda W_{2} u+\varepsilon \quad \varepsilon \mu \theta v \varepsilon: \quad \varepsilon \sim(0, \Omega) 5
\end{aligned}
$$

Em que "IP1" representa a variável dependente, proxy que identifica privações múltiplas em educação, saúde e padrão de vida nos mesmos domicílios; " $\beta_{0}$ " é a constante; " $\beta_{1}$ " é o coeficiente que acompanha a variável explicativa do componente IDH-R, representado pelo

\footnotetext{
${ }^{4}$ Testaram-se matrizes de $\mathrm{K}$ vizinhos mais próximos (onde $\mathrm{K}=1, \ldots, 20$ ), matrizes de contiguidade convencionais Rainha e Torre e suas versões para os vizinhos de segunda ordem (Rainha 2 e Torre 2), além das matrizes de distância euclidiana. Tal procedimento para selecionar a matriz de pesos espaciais baseia-se em Baumont (2004, p.13) e vem sendo utilizado por diversos autores (OLIVEIRA et al., 2011; MARANDUBA JR; ALMEIDA, 2009).
} 
"R", o padrão de vida (renda); " $\beta_{2}$ " é o coeficiente que acompanha a variável explicativa analfabetismo "E", que representa a ausência de acesso ao conhecimento (educação); " $\beta_{3}$ ” é o coeficiente que acompanha a variável explicativa mortalidade infantil "S", proxy da ausência de saúde; " $\beta 4$ " é o coeficiente que acompanha a variável explicativa "L", representa o IDH-L, proxy de uma vida longa e saudável (saúde), medida pela expectativa de vida e longevidade; e " $\beta_{5}$ " é o coeficiente que acompanha a variável explicativa " $T$ ", representa a medida de desigualdade de renda de Theil, que varia de 0 até 1, em que 0 representa a perfeita distribuição de renda e 1 representa a total concentração de renda. E "u" representa um termo de erro, que segue um processo espacial autorregressivo; " $\lambda$ ” representa o coeficiente escalar do erro espacial"; " $\rho$ " é o coeficiente de defasagem espacial ${ }^{6}$ (um escalar); "W" representa a mesma matriz de pesos espaciais utilizada no cálculo do $I$ de Moran (Distância Euclidiana); e " $\varepsilon$ " é o termo de erro ${ }^{7}$.

Logo, as equações para o modelo de determinante da pobreza podem ser expressas em sua forma logarítmica "In (IP1)", lembrando que, segundo Anselin (1988) e Anselin e Bera (1998), os modelos tradicionais de regressão linear, que não levam em conta os efeitos espaciais (autocorrelação e heterogeneidade espaciais), não devem ser estimados pelo método dos mínimos quadrados ordinários, pois as estimativas serão inconsistentes e/ou ineficientes ${ }^{8}$.

Assim, o modelo incorpora as duas formas de autocorrelação citadas, de erro e defasagem espaciais. Cabe ressaltar que as matrizes utilizadas $\left(\mathrm{W}_{1} \text { e } \mathrm{W}_{2}\right)^{9}$ contêm pesos espaciais diferentes, constituindo um caso mais geral.

\footnotetext{
${ }^{5}$ Se $\lambda$ assumir valor nulo, não existe autocorrelação espacial do erro. De acordo com Rey e Montouri (1999), quando $\lambda \neq 0$, um choque ocorrido em uma unidade geográfica se espalha não só para seus vizinhos imediatos, mas por todas as outras unidades. Esse tipo de dependência espacial poderia ser resultante de efeitos não modelados, que não são aleatoriamente distribuídos através do espaço. Portanto, não considerar esse tipo de efeito espacial, quando se mostrar relevante, gera estimativas ineficientes.

${ }^{6}$ Este elemento na forma funcional pode ser entendido como uma média dos valores da pobreza das regiões vizinhas. Se $\rho=0$, pode-se constatar que não há autocorrelação espacial no modelo. Porém, $\rho \neq 0$ sugere a existência de autocorrelação espacial. Além disso, da mesma forma que o Modelo com Erro Espacial, quando $\rho \neq 0$, um choque ocorrido em uma unidade geográfica se espalha não só para os seus vizinhos imediatos, mas por todas as outras unidades (ANSELIN; BERA, 1998, p. 246).

${ }^{7}$ Lembrando que " $\varepsilon$ " representa um termo de erro normalmente distribuído, com média zero e variância constante.

${ }^{8}$ Portanto, para não incorrer em estimativas inconsistentes e/ou ineficientes, analisou-se a necessidade de incluir efeitos espaciais ao modelo. Para tanto, segue-se a proposta feita por Florax, Folmer e Rey (2003: primeiramente, estima-se o modelo clássico de análise de regressão linear por MQO; em seguida, testa-se a hipótese de ausência de autocorrelação espacial, devido a uma defasagem ou a um erro por meio do valor do multiplicador de Lagrange para defasagem espacial (ML $\rho$ ) e Multiplicador de Lagrange para o erro espacial (ML $\lambda$ ). Caso nenhum dos dois testes seja significativo, a utilização do modelo clássico é mais apropriada. Caso contrário, é necessário seguir o próximo passo. Caso ambos sejam significativos, estima-se o modelo apontado como o mais significante de acordo com as versões robustas desses testes, ou seja, o multiplicador de Lagrange robusto para a defasagem espacial (MLR $\rho$ ) e o multiplicador de Lagrange robusto para o erro espacial (MLR $\lambda$ ). Assim, se MLR $\rho>$ MLR $\lambda$, usa-se o modelo com defasagem espacial como o mais apropriado. Se, ao contrário, MLR $\rho<$ MLR $\lambda$, adota-se o modelo de erro espacial como o mais apropriado.

${ }^{9}$ W1 é a matriz Euclidiana, e W2 é a matriz de pesos espaciais binários, com a convenção de contiguidade "rainha".
} 


\subsection{Fonte de dados}

As regiões utilizadas foram as localidades formadas pelos bairros de Salvador, com a quantidade de domicílios e o número de habitantes de cada um, para compor as dimensões analisadas. Para as dimensões habitação/saneamento e renda, a unidade de análise foi o domicílio, e para as dimensões saúde e educação, a unidade foi o indivíduo. Foram utilizados dados dos censos de 2000 e 2010, para os 163 bairros de Salvador, obtidos através do Banco de Dados por Setores Censitários do PNUD (2014).

Na composição do trabalho, foram utilizados os softwares ArcGis10.1 para integração das bases de dados com os arquivos shapefile e elaboração dos mapas, o GeoDa Space para análise espacial econométrica, o Excel12 para construção dos rankings de pobreza, além do GeoDa8.4 para cálculo da matriz de vizinhança e análise espacial.

Para o modelo de regressão espacial, a variável dependente foi o IP1, calculado no estudo, e as variáveis explicativas Índice de Renda do IDH-R, índice de longevidade do IDHL, Analfabetismo, índice de Theil e mortalidade infantil até 05 anos. As variáveis explicativas utilizadas tiveram como referencial o trabalho de Giovanetti e Raiher (2015) e Sen (1988), trabalho empírico feito para os municípios do Paraná, com dados do Censo demográfico, em que o PIB per capita tem relação inversamente proporcional com a Pobreza.

Em vista disso, o foco da aplicação do modelo de econometria espacial é verificar a relação dos determinantes e averiguar quais variáveis são representativas para explicar a pobreza nos bairros de Salvador, em 2000 e 2010.

\section{$4 \quad$ RESULTADOS E DISCUSSÕES}

Inicialmente foi feita uma análise exploratória e descritiva das dimensões que compõem o IP, ficando evidente, conforme Gráfico 1, que, das quatro dimensões utilizadas, a saúde foi a que apresentou a maior participação absoluta média na composição do IP nos bairros, com mais de $40 \%$ em 2000 e quase $20 \%$ em 2010 , seguida pela renda, que apresenta uma contribuição média de $20 \%$ em 2000 e quase $10 \%$ em 2010. Por sua vez, a dimensão habitação/saneamento representou apenas 10\% na composição do IP em 2000 e 14\% em 2010. Por último, representada como menor impacto sobre o IP, ficou a dimensão educação, com aproximadamente $7 \%$ em 2000 e $4 \%$ em 2010. 
Gráfico 1 - Contribuição absoluta média das dimensões da pobreza na composição IP nos bairros de Salvador/2000 e 2010

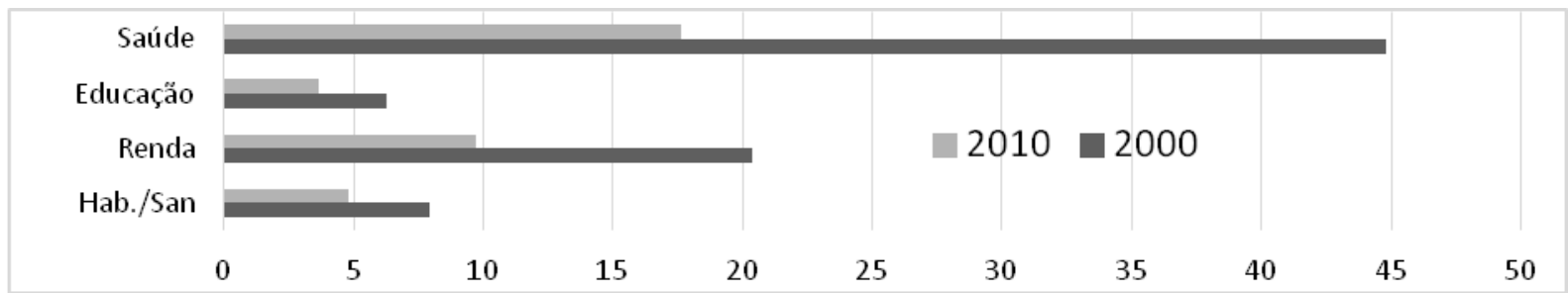

Fonte: elaboração própria, tendo como referência o banco de dados dos setores censitários da PNUD (2014).

Das dimensões analisadas, a saúde foi a que apresentou a maior variação no período em estudo, com redução superior a 50\%, isto é, colaborou sensivelmente com a diminuição da pobreza em Salvador. Nas outras dimensões, a redução de 2000 em relação a 2010 foi significativamente menor. Além disso, os resultados indicaram que a pobreza multidimensional no município foi mais significativa que a pobreza utilizando apenas a renda, representando um maior impacto na composição média do IP, o que evidencia que os estudos e as políticas de alívio para essa problemática devem considerar no seu escopo teórico e metodológico outras dimensões que não a renda, pois, segundo Sen (1999), esse não é o único aspecto a causar privações de capacidades, existem muitos outros que influenciam na privação das capacidades básicas dos indivíduos, ou seja, a pobreza real.

Avaliando a incidência absoluta média do Índice de Pobreza nos bairros de Salvador, Gráfico 2, observou-se que a incidência da pobreza multidimensional medida pelos IPs 1 e 2 foi superior à pobreza medida pelo IP3, utilizando apenas a renda, nos dois períodos analisados. Entretanto, registrou-se também redução da pobreza multidimensional de 2000 para 2010 e da pobreza unidimensional. É perceptível que no período de 2010 a diferença entre os índices foi reduzida sensivelmente. Salienta-se que essa redução da pobreza multidimensional pode ter sido influenciada, principalmente, pela melhora no indicador da dimensão saúde, redução da mortalidade infantil, significativa no período analisado, e pela redução registrada no alfabetismo e condições de moradia. Destaca-se ainda redução da pobreza por renda, que pode ter possibilitado melhores condições de vida para a população.

Gráfico 2 - Incidência absoluta média dos IPs nos bairros de Salvador, em 2000 e 2010

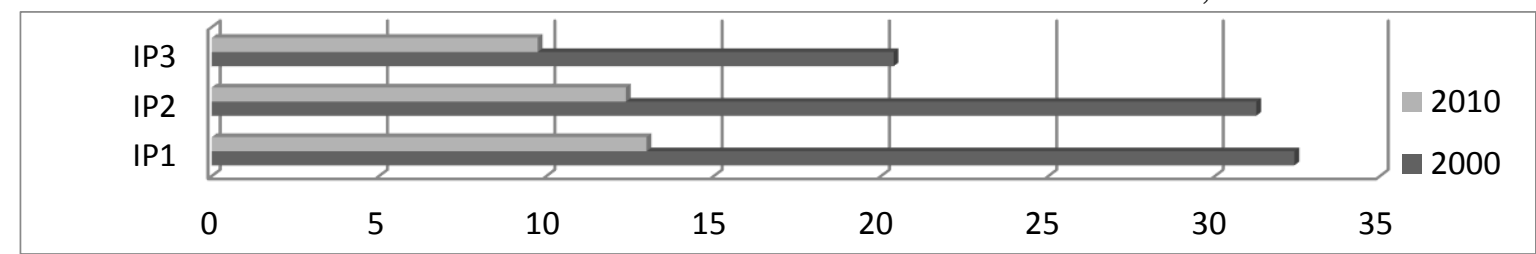

Fonte: elaboração própria, tendo como referência o banco de dados dos setores censitários da PNUD (2014).

Analisando descritivamente as informações para 2000, Tabela 1, foi possível inferir que 
mais da metade dos bairros soteropolitanos apresentaram pobreza multidimensional maior que a média do município, por terem média menor que a mediana para os índices multidimensionais, fato que não se verifica para o índice unidimensional, que apresenta média maior que a mediana, apontando pobreza por ter renda menor que a média do município. Porém a variância, em todos os índices de pobreza, com valores superiores a 90\%, indica grande dispersão das informações em torno da média, significando presença de informações discrepantes ou outliers. Todavia, para 2010, percebe-se uma relação contrária ao período anterior, pois os três índices em análise apresentam médias superiores à mediana, apontando que a pobreza nesse período, nos bairros de Salvador, foi superior à média do município. É possível concluir também que houve redução na dispersão das informações, apontada pela variância em torno da média, com valores abaixo de $34 \%$ para os índices multidimensionais. Contudo a renda continua bastante dispersa, com variância em torno da média superior a $60 \%$, mas bem menor que no período anterior.

Tabela 1 - Estatísticas descritivas para os índices de pobreza dos bairros de Salvador, em 2000 e 2010.

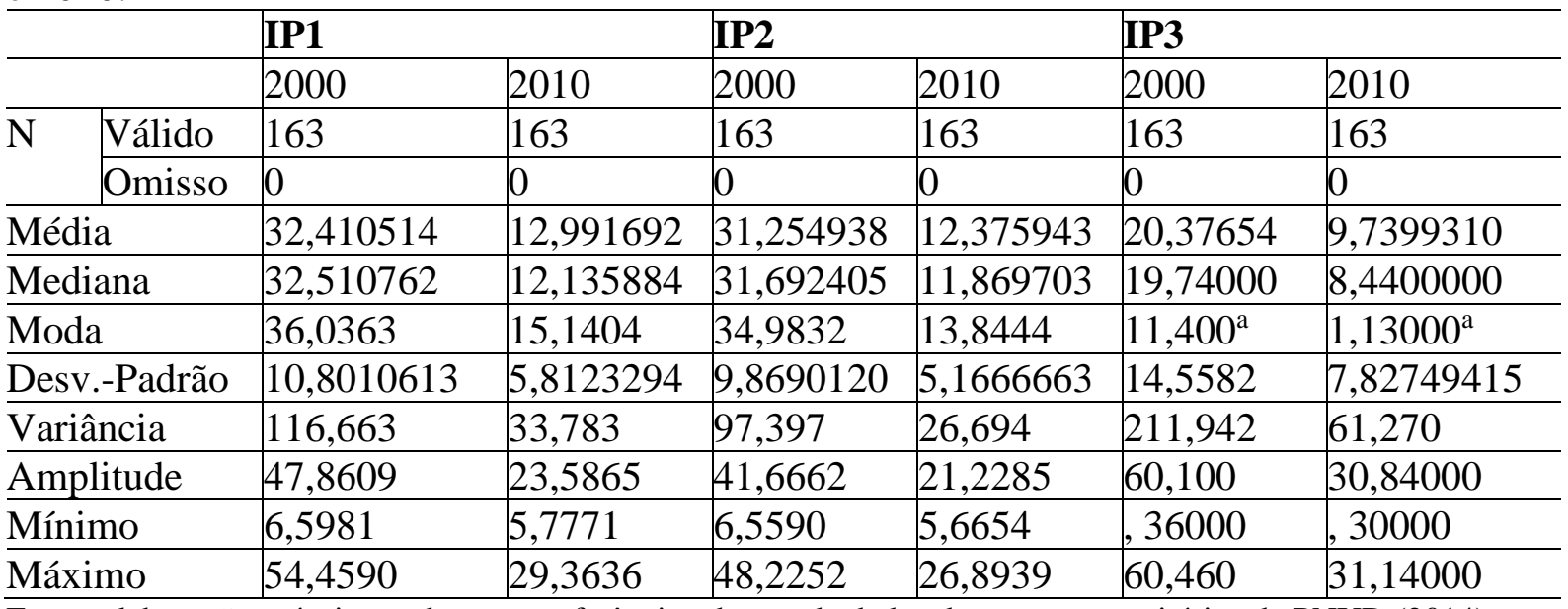

Fonte: elaboração própria, tendo como referência o banco de dados dos setores censitários da PNUD (2014), com auxílio do software SPSS23.

A Tabela 1 mostra que a pobreza multidimensional nos bairros de Salvador se reduziu, em média, de 32,41 em 2000 para 12,99 em 2010, uma redução da ordem de 59,91\% em dez anos. Observando o IP3, que considera apenas a privação por renda, a queda da pobreza, para a média dos bairros soteropolitanos, foi um pouco menor, da ordem de 52,20\%, ou seja, o valor médio do índice se deslocou de 20,37 para 9,73 em 2010. Assim, comparando a pobreza multidimensional com a unidimensional, é possível afirmar que houve redução da pobreza média de Salvador em todos os bairros entre 2000 e 2010. Essa diferença de resultado entre pobreza multidimensional (IP1) e pobreza unidimensional ou monetária (IP3), evidenciada por este estudo, permite afirmar ainda que a superação da pobreza por renda não implica atendimento de outras dimensões. Por outro lado, constatou-se também que o desempenho dos 
bairros não foi homogêneo. Enquanto em alguns o progresso, em termos de redução da pobreza, foi bem acentuado, em outros, houve apenas uma sensível melhora, o que evidencia concentração de renda nos bairros soteropolitanos e uma distribuição dos serviços essenciais para melhoria de vida da população ainda pouco eficiente.

\subsection{Ranking dos bairros de Salvador em relação à pobreza e ao desenvolvimento}

Para análise dos dados, utilizou-se uma amostra dos três bairros que se apresentaram em maior situação de pobreza e os três em menor situação, de acordo com os índices de pobreza calculados para este estudo. Dessa forma, foram criados rankings de pobreza, com os bairros em maior situação de pobreza em primeiro lugar, para todos os índices utilizados.

Nesse sentido, o bairro de Salvador que apresentou índice de maior situação de pobreza, portanto em primeiro lugar, foi a Ilha de Maré, quando avaliado o IP1, com índice de 54,46\% em 2000 e 29,36\% em 2010; em segundo lugar, está a Ilha de Bom Jesus dos Passos, com 54\% em 2000 e 40\% em 2010. Já Nova Brasília foi apontada com 54,38\%, consequentemente, ocupando a terceira colocação, tanto em 2000, e 2010com índice de pobreza equivalente a $27,07 \%$. Quando se avalia o IP2, que exclui a renda do seu escopo, fica em primeiro lugar Ilha de Maré, tanto em 2000, com 48,22\%, quanto em 2010, com 26,89\%. A segunda colocação é ocupada pelo bairro São Cristóvão, com 48,08\% em 2000, e Nova Brasília, com 26,10\% para 2010. O terceiro colocado em 2000 foi o Bairro Santa Cruz, com índice de pobreza multidimensional de 48,07\% e em 2010, novamente, o Bairro São Cristóvão, com 24,57\%.

Porém, quando se observa o comportamento dos resultados, levando em conta apenas o índice unidimensional, fica em 2000, em primeiro lugar, Ilha de Maré, com 60,46\%; em segundo, Ilha de Bom Jesus, com 60,44\%; e em terceiro, Nova Brasília, com 60,42\%. Em 2010, esse quadro aparentemente não muda, pois os mesmos três bairros do período anterior apresentam índice de pobreza de $31,14 \%, 31,11 \%$ e de $28,82 \%$, em primeiro, segundo e terceiro lugar, respectivamente.

Com relação aos menos pobres, na avaliação do IP1 e IP2, estão o Bairro Aeroporto, com índice de pobreza de 6,60\% e 6,56\%; o Bairro Nazaré, com 7,80\% e 7,98\%; e o Bairro Novo Horizonte, com 10,69\% e 10,97\% em 2000. Já em 2010, os bairros menos pobres foram: Itacaranha, com 5,77\% e 5,66\%; Caminho das Árvores, com 5,78\% e 5,67\%, e o Bairro Vitória, com 5,79\% e 5,68\%. Porém, avaliando o IP3, percebe-se que os bairros menos pobres são: Boca 
do Rio, com 0,36\%; Caminho das Árvores, com 0,74\%, e Itacaranha, com 0,75\% em 2000. Já em 2010, pontificam o Bairro Canela, com 0,30\%; Itacaranha, com 0,32\%; e o Bairro Caminho das Árvores, com índice de pobreza por renda de 0,33\%. Ressalta-se que esses resultados indicam que a redução da pobreza foi mais substancial nos bairros mais pobres que nos bairros mais ricos. O que significa que houve redução das desigualdades nos bairros de Salvador, também houve melhora na oferta dos serviços públicos, pois a pobreza multidimensional também foi reduzida de forma significativa de 2000 para $2010 \mathrm{em}$, aproximadamente, 21,33\%. Pode-se inferir nesse sentido, em conformidade com Sen (1999), que as instituições públicas se aproximaram mais da população, permitindo uma ligeira redução no fosso que separa ricos e pobres.

Como forma de verificar a consistência dos índices de pobreza, foi feita uma comparação com o IDH dos bairros de Salvador nos mesmos períodos. Os resultados confirmaram o pressuposto de que os bairros mais pobres também são os menos desenvolvidos. Nesse sentido, o bairro de Salvador que apresentou o menor resultado, tendo em vista que o IDH varia de 0 a 1, e que quanto mais próximo de 1 , maior é o nível de desenvolvimento, foi o Bairro Ilha de Maré, com índice de desenvolvimento igual a 0,435; a segunda colocação é ocupada pelo Bairro Ilha de Bom Jesus dos Passos, com 0,436, e na terceira colocação, está o Bairro Nova Brasília, com 0,437 em 2000. Já no período seguinte, 2010, estão os bairros Ilha de Maré, com 0,578; Nova Brasília, com 0,579; e Cassange, com 0,607. Por outro lado, na outra ponta do ranking, os bairros que apresentaram os melhores resultados em 2000 foram: Caminho das Árvores, com 0,909; Itacaranha, com 0,908; e Aeroporto, com 0,907. Com relação a 2010, os bairros mais desenvolvidos foram: Chapada do Rio Vermelho, com 0,959; Itacaranha, com 0,952; e Caminho das Árvores, com índice de desenvolvimento humano equivalente a 0,953 no período.

Essa comparação dos rankings mostra a consistência dos índices de pobreza utilizados neste trabalho e sugere que eles podem ser utilizados para estudar a pobreza em Salvador bem como sua distribuição espacial. Entretanto, percebe-se grande similaridade entre os bairros, tanto os que apresentaram os melhores resultados, quanto os que apresentaram os piores resultados, para todos os índices e períodos analisados, em que os bairros menos desenvolvidos também são aqueles que apresentaram os maiores índices de pobreza multidimensional assim como os menores índices são apresentados por aqueles mais desenvolvidos.

Quando os bairros são classificados pelo grau de pobreza em muito alto, alto, médio e baixo, percebe-se que os resultados dos índices corroboram a análise dos rankings, havendo 
subestimação do número de bairros em situação de pobreza quando se observa o problema apenas sob o ponto de vista da renda, Tabela 2, principalmente em 2000, quando ocorre uma discrepância mais acentuada. Porém, quando são observadas as outras dimensões e considerados com muito alto grau de pobreza aqueles bairros em que o índice foi de $50 \%$ ou mais, são encontrados 09 bairros no IP1 e nenhum no IP2 nessa condição. Entretanto, quando se classifica com graduação alta, de $30 \%$ a 49,99\%, encontram-se 87 bairros nessa condição de pobreza no IP1 e 89 no IP2. Os bairros com médio índice de pobreza, ou seja, de 15\% a 29,99\%, são 63 para o IP1 e 70 no IP2. Já os com grau de pobreza menor que 15\%, são apenas 04 bairros, tanto no IP1, como no IP2. Contudo, quando se considera somente a renda, a grande maioria dos bairros foi classificada como de baixo e médio índice de pobreza, isto é, 124, enquanto 33 foram considerados de alto índice e 06 bairros foram classificados como de muito alto grau de pobreza em 2000. Mais uma vez, os dados analisados reforçam as afirmações de Sen (1999) de que a renda não é o único fator causador de privações das necessidades básicas.

Tabela 2 - Quantidade de bairros de Salvador por grau de pobreza em 2000 e 2010

\begin{tabular}{ll|l}
\hline Quantidade de bairros em 2000 & Quantidade de bairros em 2010 \\
\hline Índice & Baixo Médio Alto M. Alto & Baixo Médio Alto M. Alto \\
IP 1 & $\mathbf{0 4} 638709$ & 1125100 \\
IP 2 & 0470890 & 1214200 \\
IP 3 & 65593306 & 12635020 \\
\hline
\end{tabular}

Fonte: elaboração própria, tendo como referência o banco de dados dos setores censitários da PNUD (2014).

Porém, quando são observados os resultados referentes a 2010, evidenciou-se um equilíbrio entre a ótica multidimensional e a unidimensional da renda, em que a grande maioria dos bairros de Salvador foi classificada como de baixo grau de pobreza, sendo 112 no IP1,121 no IP2 e 126 no IP3. Os bairros que apresentaram grau médio de pobreza foram 51 para o IP1,42 no IP2 e 35 no IP3. Já os classificados com alto e muito alto grau de pobreza, nos índices multidimensionais, nenhum bairro foi encontrado no período nessa situação. Contudo o IP3 registra apenas 02 bairros com alto grau de pobreza e nenhum bairro com muito alto grau de pobreza no período analisado.

Assim, esses resultados reforçam a tese de que Salvador tinha uma alta pobreza multidimensional em 2000. Todavia, na década seguinte, houve redução, simultaneamente, nos índices multidimensionais e unidimensional, provavelmente provocada pela oferta de melhores serviços públicos, mas principalmente pelas políticas de transferências de renda, como o programa Bolsa Família, por exemplo, que contribuiu sobremaneira para reduzir a pobreza nos bairros da capital baiana, principalmente nos mais pobres. 


\subsection{Análise espacial da pobreza nos bairros de Salvador}

O mapa de distribuição da pobreza nos bairros de Salvador para o período de 2000, na Figura 3, mostra a existência de regiões pobres e não pobres, onde o IP3 e o IP2 apresentaram resultados muito semelhantes, sendo a diferença, portanto, entre a pobreza multidimensional e a unidimensional quase imperceptível. Fica porém evidente que a alta pobreza está distribuída espacialmente por todo o município, com maior concentração no seu extremo norte ${ }^{10}$.

Figura 3 - Mapas de distribuição da pobreza nos bairros de Salvador (2000)

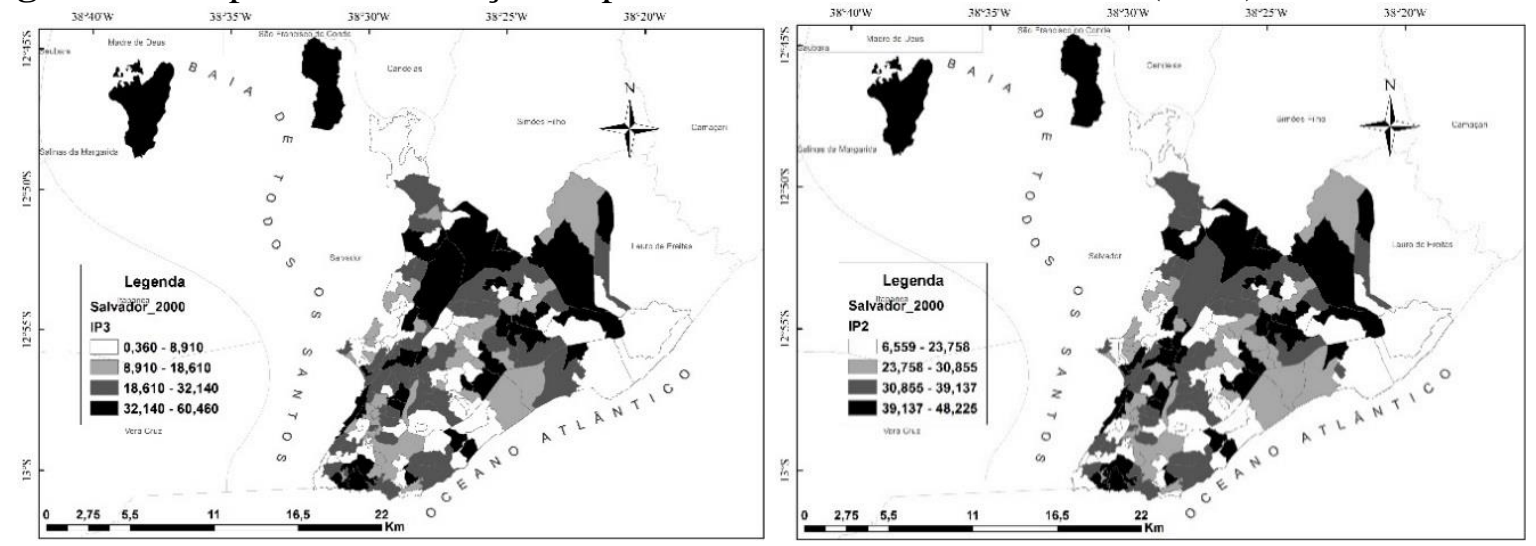

Fonte: elaboração própria, tendo como referência o banco de dados dos setores censitários da PNUD (2014), com auxílio do software ArcGis10.1.

Em relação a 2010, não houve diferença na distribuição, apesar do registro de redução da pobreza em todos os índices. Entretanto, o padrão espacial continuou o mesmo do período anterior, tendo os mapas ratificado as análises anteriores, tanto dos rankings quanto da classificação de bairros. Além disso, os resultados dos mapas fortalecem a discussão da utilização de outras dimensões para o estudo da pobreza, evidenciando também a presença de aglomerações de regiões pobres e não pobres, que podem ser observadas e analisadas pela aplicação do I de Moran Local, sendo possível detectar a presença de clusters de pobreza (ANSELIN, 1988).

Dessa forma, buscou-se visualizar e entender a espacialização da pobreza nos bairros de Salvador e calculou-se o Índice de Moran para os três índices em estudo (Tabela 3). Logo, considerando esse índice, foi possível medir a existência de autocorrelação espacial, em que o gráfico de dispersão aponta para a existência ou não de agrupamentos espaciais, para uma dada variável. Nessa lógica, quanto mais próximo de um, maior o grau de autocorrelação. Esse índice

\footnotetext{
${ }^{10}$ Salienta-se que o software ArcGis10.1 utiliza os valores máximo e mínimo de cada ranking para determinar os intervalos de análise, daí os resultados serem diferentes dos utilizados anteriormente na graduação dos rankings, que variam de 0 a 100 .
} 
permite verificar se os dados estão ou não correlacionados espacialmente (ALMEIDA, 2012; ANSELIN, 1988).

Observando os resultados dos índices multidimensionais, foi possível perceber uma autocorrelação espacial positiva com I de Moran igual a 0,027 e 0,021, com uma pseudosignificância com p-valor correspondente a 1\% para 2000. Isto mostra uma baixa autocorrelação espacial, com grande dispersão das informações, ao mesmo tempo em que evidencia a presença de clusters, com poucas diferenças entre os dois índices, além da possibilidade de presença de outliers. Entretanto, o IP3 registra maior dispersão das informações, indicando autocorrelação positiva maior da pobreza por renda nos bairros de Salvador, com I de Moran equivalente a 0,047 e pseudo $p$-valor referente a 1\%, mas também muito próximo dos valores dos índices multidimensionais. No geral, esses resultados sugerem presença de regimes espaciais semelhantes, ou seja, regiões próximas espacialmente com valores parecidos, o que está coerente com a análise anterior. Para 2010, os valores foram maiores, mas vão na mesma direção, apontando uma autocorrelação positiva, porém considerada baixa em todos os três índices utilizados.

Tabela 3 - Índice de Moran do IP1, IP2 e IP3 para os bairros de Salvador, em 2000 e 2010.

\begin{tabular}{llll}
\hline & IP1 & IP2 & IP3 \\
\hline $\mathbf{2 0 0 0}$ & 0,027 & 0,021 & 0,047 \\
\hline $\mathbf{2 0 1 0}$ & 0,048 & 0,038 & 0,059
\end{tabular}

Fonte: elaboração própria, tendo como referência o banco de dados dos setores censitários da PNUD (2014).

As análises espaciais feitas até o momento tiveram por base medidas globais e, de acordo com Almeida (2012), deve-se ter em mente que essas medidas podem mascarar a existência de associações locais. Assim, a busca por associações locais lineares, estatisticamente significantes, pode ser feita com a utilização do Indicador Local de Associação Espacial (LISA) ${ }^{11}$.

Sendo assim, a aplicação do Índice Local de Moran permite que se identifiquem os clusters (ou manchas de pobreza) com base nos resultados do Índice de Moram Global, nesse caso, comparam-se os indicadores e seus vizinhos, verificando se há concentrações espaciais locais ou não, com resultados semelhantes ${ }^{12}$. Isto posto, é possível visualizar o comportamento

\footnotetext{
${ }^{11} \mathrm{O}$ software GeoDa8.4 já estipula a significância em 999 permutações, ou seja, o estudo é significante em 0,001\%. Isto é, sua aplicação, obedecendo às mesmas características, tem $99,9 \%$ de chance de obter o mesmo resultado. Porém, para este estudo foi considerada uma significância mínima de $95 \%$.

${ }^{12}$ O LISA executa a decomposição do indicador global de autocorrelação na contribuição local de cada observação em quatro categorias, cada uma, individualmente, correspondendo a um quadrante no diagrama de dispersão de Moran. Ou seja, High-Low, vizinhos com valores altos cercados por valores baixos, High-High, vizinhos de altos valores rodeados por vizinhos semelhantes, Low-Low, formado por regiões de valores
} 
desses índices para o período em estudado, através do LISA Maps ou mapas de clusters (Figura $4)^{13}$.

Figura 4 - Mapas de concentração da pobreza para os bairros de Salvador em 2000

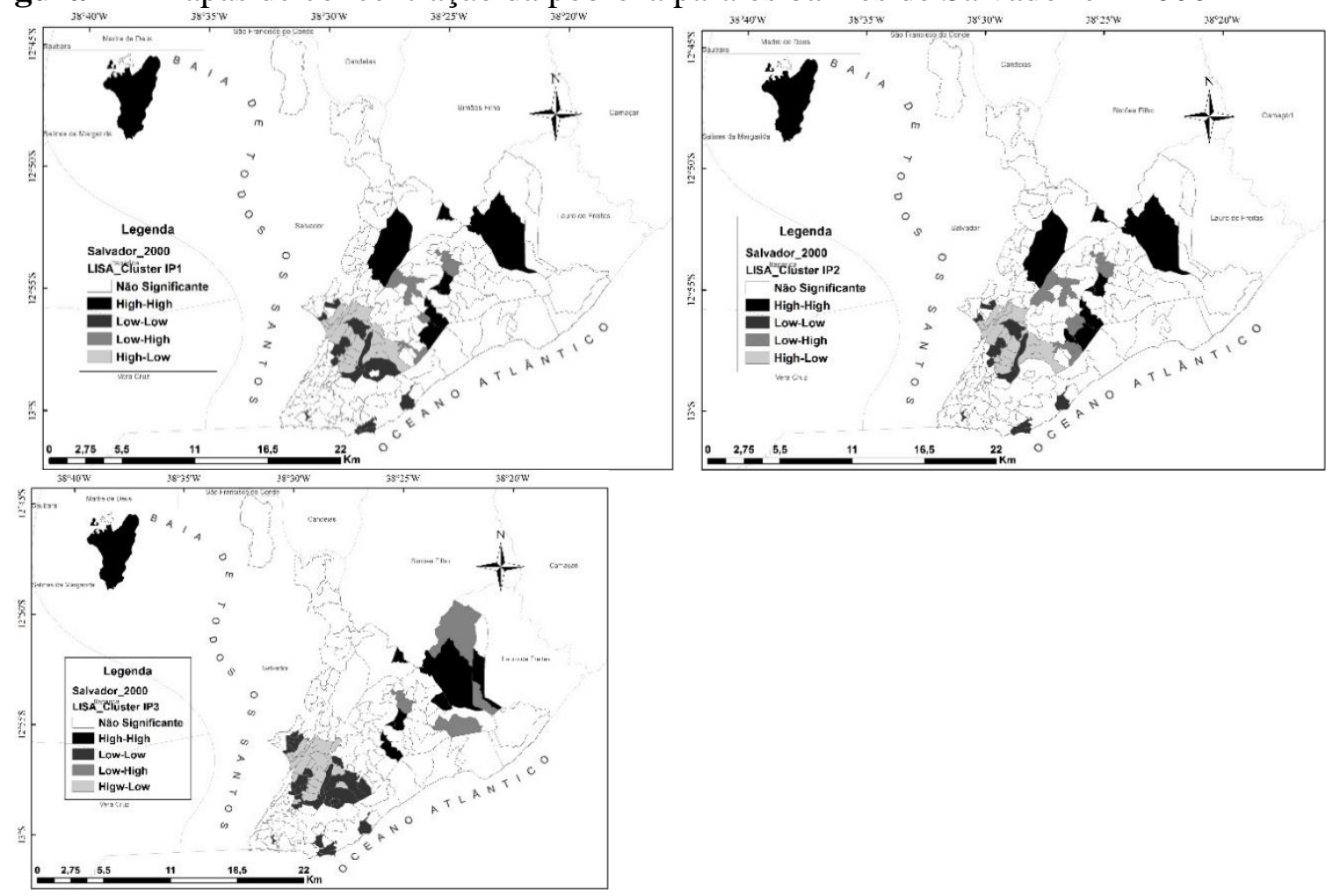

Fonte: elaboração própria, tendo como referência o banco de dados dos setores censitários da PNUD (2014), com auxílio do software ArcGis10.1.

Na observação dos mapas, ficou constatado que tanto os resultados obtidos para a o IP1 como para IP2 apresentaram clusters de bairros com alta pobreza, rodeados por bairros de alta pobreza, localizados nas regiões norte, mais aproximadamente, na região onde se localiza o bairro Cassange e outras áreas espalhadas na região do Centro Administrativo, onde ambos os índices têm a mesma formatação, com raríssimas diferenças. Destaca-se também a presença de um grande cluster de baixa pobreza rodeado por regiões também de baixa pobreza, localizado na região central do município, próximo ao bairro Retiro. É possível perceber também pequenas ilhas de baixa pobreza, ou Low-Low, principalmente no litoral sul, assim como algumas ilhas de alta pobreza, ou High-High, na zona norte de Salvador, o que pode ser denominado como possíveis outliers, isto é, bairros que apresentaram resultados discrepantes em relação à média dos vizinhos. 
Com relação ao IP3, observou-se formatação dos clusters bem parecida com os índices multidimensionais. Houve presença de clusters em regiões com resultados semelhantes, classificados como High-High, envolvendo a região norte, principalmente nos bairros de Itinga e Cassange, rodeados por bairros na mesma condição, ou seja, que também apresentam alto índice de pobreza. Por outro lado, há presença de clusters, com bairros classificados como LowLow, como nos índices multidimensionais, na mesma região do Retiro, que, igualmente, é rodeada por um cluster High-Low, ou seja, baixa pobreza rodeada por alta pobreza, além de evidenciar a presença de alguns bairros com valores discrepantes. Em relação aos dois índices anteriores, as diferenças não foram significativas, poucas alterações foram registradas entre os dois métodos de aferição da pobreza.

Em relação a 2010, Figura 5, os resultados da análise de cluster confirmaram a hipótese levantada anteriormente em relação à manutenção do padrão espacial de uma década para outra.

Figura 5 - Mapas de concentração da pobreza para os bairros de Salvador (2010)
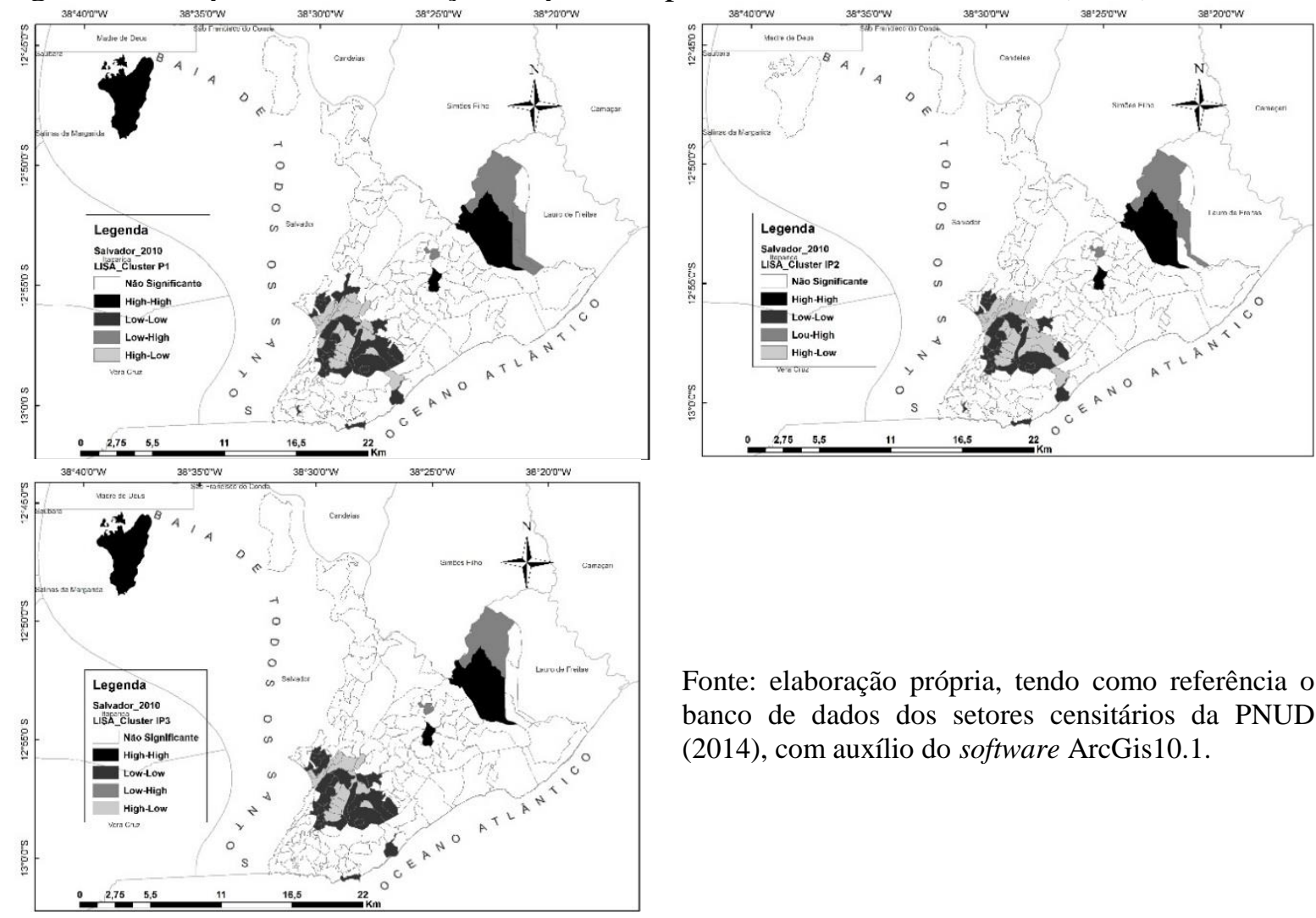

As regiões de alta pobreza rodeadas também por alta pobreza continuaram as mesmas, localizadas na zona norte de Salvador, assim como as de baixa pobreza rodeadas por bairros também de baixa, que continuaram no bairro Retiro. As pequenas diferenças apresentadas foram em relação ao cluster High-Low, que reduziu de tamanho, o que pode indicar redução nos índices de pobreza, como já sinalizado. Tais resultados do Índice Local de Moran 
corroboraram as análises feitas anteriormente com o índice global, bem como as outras análises feitas. Portanto, evidenciou-se a presença de clusters de pobreza nos bairros de Salvador, independentemente do índice utilizado para sua aferição. Salienta-se que, nos dois períodos em estudo, os bairros que não apresentaram coloração foram classificados como não significantes, isto é, não apresentaram resultados próximos da média dos vizinhos.

\subsection{Análise econométrica espacial para os bairros de Salvador 2000/2010}

Como apresentado por Florax, Folmer e Rey (2003), utilizou-se para esta análise, primeiramente, o Método dos Mínimos Quadrados Ordinários, que gerou a regressão apresentada na Tabela 4 e testou todas as variáveis do modelo. O diagnóstico da regressão de dependência espacial revelou fraca dependência espacial tanto para a defasagem quanto para o erro espacial em 2010, enquanto em 2000 não houve significância estatística em relação à dependência espacial.

Tabela 4 - Regressão do índice de pobreza contra seus determinantes nos bairros de Salvador e seus vizinhos para 2000 e 2010 , pelo método M. Q. O.

\begin{tabular}{|c|c|c|c|c|c|c|}
\hline \multicolumn{7}{|c|}{ Resultado 2000} \\
\hline \multirow[t]{2}{*}{$\ln (\mathrm{IP} 1)=$} & 0.2456 & $-0.7629 \ln (\mathrm{L})$ & $-0.1114 \ln (\mathrm{R})$ & $+0.0092 \ln (\mathrm{E})$ & $+0.7933 \ln (\mathrm{S})$ & $+0.0683 \ln (\mathrm{T})$ \\
\hline & $(4.613)^{*}$ & $(-4.4858)^{*}$ & $(-1.857) * * *$ & $(2.248)^{* *}$ & $(38.238)^{*}$ & $(4.747)^{*}$ \\
\hline ano & & F-statistic & $\mathrm{N}$ & C. I. Akaike & C. Schwarz & R-squared \\
\hline 2000 & & $7343.6161 *$ & 163 & $-734,769$ & $-716,207$ & 0.9957 \\
\hline \multicolumn{2}{|c|}{ Jarque-Bera test } & \multicolumn{2}{|c|}{ Breusch-Pagan test } & \multicolumn{2}{|c|}{ Koenker-Bassett test } & \\
\hline & $7572.992 *$ & & $1676.286^{*}$ & & $95.065^{*}$ & \\
\hline \multicolumn{7}{|c|}{ Diagnósticos de dependência espacial } \\
\hline \multicolumn{3}{|c|}{ Lagrange Multiplier (SARMA) } & 1,371 & \multicolumn{2}{|l|}{ Moran's I (error -) } & 0,394 \\
\hline \multicolumn{3}{|c|}{ Lagrange Multiplier (lag $-\rho)$} & 1,37 & \multicolumn{2}{|l|}{ Robust LM (lag) } & 1,366 \\
\hline \multicolumn{3}{|c|}{ Lagrange Multiplier (error) } & 0,005 & \multicolumn{2}{|c|}{ Robust LM (error) } & 0,001 \\
\hline \multicolumn{7}{|c|}{ Resultados 2010} \\
\hline \multirow[t]{2}{*}{$\ln (\mathrm{IP} 1)=$} & -0.1804 & $-0.7035 \ln (\mathrm{L})$ & $-0.0410 \ln (\mathrm{R})$ & $+0.0038 \ln (\mathrm{E})$ & $+0.9248 \ln (\mathrm{S})$ & $+0.0680 \ln (\mathrm{T})$ \\
\hline & $(-1.974)^{* *}$ & $(-3.367)^{*}$ & $(-0.948)$ & $(1.421)$ & $(19.187)^{*}$ & $(7.279)^{*}$ \\
\hline ano & & F-statistic & $\mathrm{N}$ & C. I. Akaike & C. Schwarz & R-squared \\
\hline 2010 & & $20555.7340 *$ & 163 & -859537 & -840975 & 0.9985 \\
\hline \multicolumn{2}{|c|}{ Jarque-Bera test } & \multicolumn{2}{|c|}{ Breusch-Pagan test } & \multicolumn{2}{|c|}{ Koenker-Bassett test } & \\
\hline & $17.760 *$ & & $26.116^{*}$ & & $18.814^{*}$ & \\
\hline \multicolumn{7}{|c|}{ Diagnósticos de dependência espacial } \\
\hline \multicolumn{3}{|c|}{ Lagrange Multiplier (SARMA) } & $7.810^{* *}$ & \multicolumn{2}{|l|}{ Moran's I (error -) } & $2.343^{* *}$ \\
\hline \multicolumn{3}{|c|}{ Lagrange Multiplier (lag $-\rho$ ) } & $4.858 * *$ & \multicolumn{2}{|l|}{ Robust LM (lag) } & $4.531 * *$ \\
\hline \multicolumn{3}{|c|}{ Lagrange Multiplier (error) } & $3.2729 * * *$ & \multicolumn{2}{|l|}{ Robust LM (error) } & $2.952 * * *$ \\
\hline
\end{tabular}

Fonte: elaboração própria, tendo como referência o banco de dados dos setores censitários da PNUD (2014), com base no GeodaSpace.

Nota: valores entre parênteses são estatísticas - t: * nível de significância de 1\%; **nível de significância de 5\%; *** nível de significância de $10 \%$.

Adicionalmente, os Testes Koenker-Bassett e Breusch-Pagan revelaram presença de heterocedasticidade nas duas regressões cross-section para 2000 e 2010. Já a multicolinearidade apresentou-se controlada, correspondendo ao valor recomendado por Anselin (1992). O teste de Jarque-Bera, que tem como hipótese nula a normalidade, apresentou p-valor > 0,05, ou seja, 
não se rejeita a hipótese nula de normalidade. Os erros apareceram indicados como não normais, porém com problemas de heterocedasticidade. Contudo, sugere-se a utilização do Método dos Mínimos Quadrados Generalizados Factíveis (MQGF) para geração do modelo ${ }^{14}$.

Nesse sentido, a aplicação do modelo de Defasagem Espacial (lag) para a variável pobreza multidimensional (IP1) não se mostrou significante pelo teste z, muito provavelmente pela presença de heterocedasticidade, mas o método MQO apontou significância de 5\% no multiplicador de Lagrange, estimado para defasagem espacial para $2010^{15}$, fato que não se verifica em 2000, sugerindo não ter ocorrido dependência espacial no período.

Diante dos resultados apresentados nas duas regressões, tanto de 2000 como de 2010 , constatou-se que o modelo se mostrou ajustado com o $\mathrm{R}^{2}$ igual a 0,99. Com exceção das variáveis renda e educação em 2010, todas as outras foram estatisticamente significativas a nível de $10 \%$, com sinal esperado compatível com a teoria econômica.

Por consequência, seguindo o arcabouço metodológico, optou-se pelo modelo de defasagem espacial, portanto estimando um modelo econométrico espacial com dados crosssection, tanto para 2000, como 2010, visando a identificar os fatores determinantes da pobreza nos bairros de Salvador (Tabela 5). Desta forma, o parâmetro " $\rho$ " se mostrou significante a 5\% pelo teste z para 2010 e permitiu constatar que as variáveis explicativas permaneceram com o sinal esperado e significativas estatisticamente de acordo com a teoria, para ambos os períodos em análise.

Desse modo, a variável "ln (R)", que representou a renda média do bairro, mostrou-se coerente com a teoria econômica, sugerindo que, em locais de maior concentração de pobreza, haverá uma consequente redução da renda, não tendo esta variável apresentado significância estatística. Ressalta-se que, apesar de a variável renda per capita ter deixado de ser significante, continuou com sinal correto, e isto não invalidou os resultados encontrados, pois, conforme Araújo, Morais e Cruz (2012), analisar a pobreza multidimensional é utilizar diversas variáveis, fragmentando-as em dimensões (renda, educação, saúde, dentre outras). Segundo os autores, a pobreza multidimensional é mais eficaz, visto que, ao tratar a pobreza somente pela ótica de uma dimensão, pode-se estar negligenciando seu real tamanho numa determinada região.

\footnotetext{
${ }^{14}$ No presente artigo, usou-se a matriz de variância-covariância de White para acomodar a heterocedasticidade. A matriz de White também é utilizada por Maranduba Jr \& Almeida (2009) e Oliveira et al. (2011).

${ }^{15}$ Um modelo de erro heterocedástico é um caso especial de um modelo em que os erros não são esféricos, de acordo com Anselin (1992), em que se verifica presença de heterocedasticidade (variância não constante dos erros), não estando sendo representada a autocorrelação espacial. Contudo, na prática, em virtude do imbricamento entre os efeitos espaciais, é possível observar o aparecimento conjunto de heterocedasticidade e autocorrelação espacial. Nesse sentido, utilizou-se a matriz de variância-covariância consistente de White para acomodar a heterocedasticidade.
} 
Tabela 5 - Regressão do modelo de defasagem espacial do índice de pobreza contra seus determinantes nos bairros de Salvador e seus vizinhos para os anos de 2000 e 2010, pelo método M. Q. G. F.

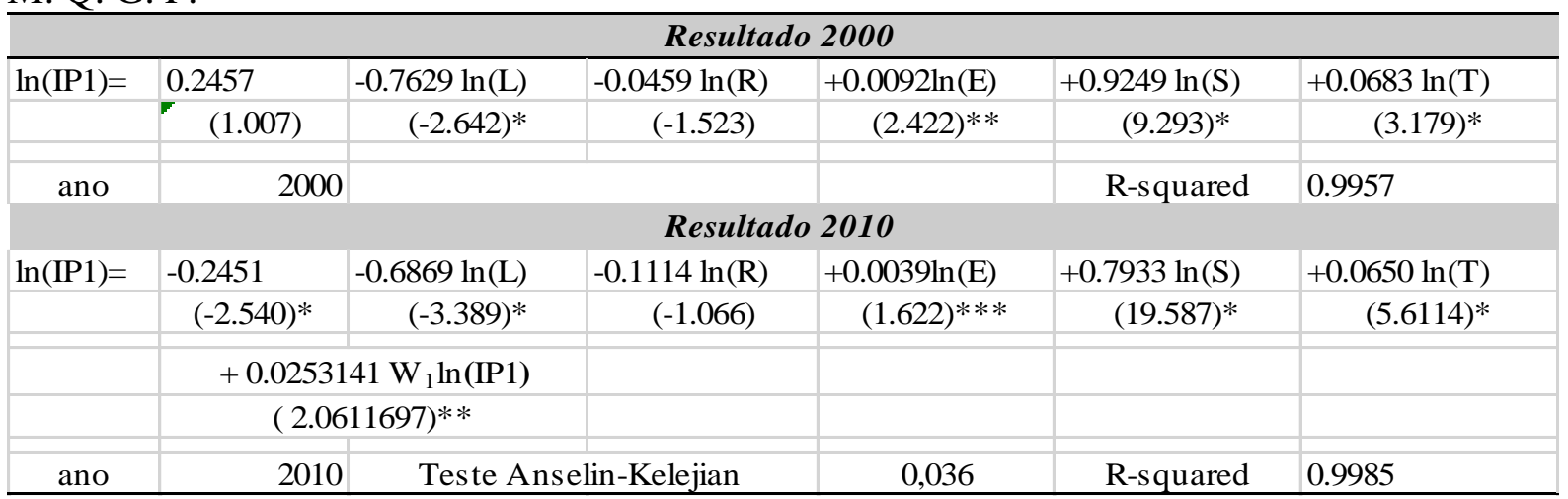

Fonte: elaboração própria, tendo como referência o banco de dados dos setores censitários da PNUD (2014), com auxílio do Spacestat para elaboração dos cálculos.

Nota1: Chamou-se de Mínimos Quadrados Generalizados Factíveis (MQGF).

Nota 2: valores entre parênteses são estatísticas - z. * nível de significância de 1\%; **nível de significância de $5 \%$; *** nível de significância de $10 \%$.

A variável "In (L)", que representa a longevidade, apresentou correlação negativa com o índice de pobreza, pois nos bairros com maiores taxas de pobreza, a longevidade e a expectativa de vida foram mais baixas, sugerindo o resultado que um aumento de $1 \%$ da longevidade provoca uma redução na pobreza multidimensional de $0,76 \%$ para 2000 e $0,68 \%$ para 2010.

Já a variável "In (E)" expressa o percentual de analfabetismo nos bairros de Salvador ou a ausência de acesso ao conhecimento, tendo os resultados mostrado relação positiva, em que quanto maior o analfabetismo, maior a concentração de pobreza nos bairros, ou seja, uma redução de $1 \%$ do analfabetismo gera uma redução na pobreza multidimensional em 0,009\% em 2000 e 0,004\% em 2010. Mesmo sob o prisma da ampliação do conceito de bem-estar, conforme analisado por Amartya Sen, a educação continua sendo associada à superação da pobreza por renda, uma vez que o maior nível de educação formal é identificado como maior potencial econômico.

No caso do "In (S)", "Mortalidade Infantil", são representadas precárias condições de saúde. Como observado, existe uma correlação positiva entre mortalidade infantil nos bairros e índice de pobreza, ou seja, os bairros com maiores taxas de pobreza foram aqueles em que a mortalidade infantil ocorreu com mais frequência, ou seja, um aumento de $1 \%$ na mortalidade infantil está associado a um aumento de 0,92\% na pobreza multidimensional em 2000 e 0,79\% em 2010.

O índice de Theil (concentração de renda), representado por "In (T)", também influenciou positivamente o aumento da pobreza dos bairros de Salvador, em que um aumento 
na desigualdade de renda de $1 \%$ também gera acréscimos na pobreza multidimensional de 0,068\% para o período 2000 e 0,065\% para 2010. Assim, o índice de Theil comprovou que quanto maior a concentração de renda, piores serão as condições de bem-estar da população soteropolitana. Resultado semelhante foi encontrado por Giovanetti e Raiher (2015) utilizando o Índice de Gini para os municípios do estado do Paraná, que também tiveram uma relação positiva.

Defende-se que os resultados obtidos para as elasticidades renda-pobreza Ln (R) e redistribuição-pobreza Ln (Theil) neste estudo se aproximam de outros trabalhos realizados para o Brasil, ao indicar que a desigualdade contribui de maneira mais representativa para os mais pobres do que o aumento da renda (TAQUES; OLIVEIRA, 2014; PINTO; OLIVEIRA, 2010; NEDER; SILVA, 2004; HOFFMANN, 2005). Contudo, há de se ressaltar que a magnitude das elasticidades varia entre os trabalhos que utilizam a metodologia econométrica, pelas formas funcionais adotadas nos modelos, pelos indicadores utilizados ou mesmo pelo nível de análise. Segundo Adams (2002), o efeito que o crescimento econômico exerce sobre a pobreza é dado pelo grau de desigualdade, então a desigualdade deve ser utilizada como controle para qualquer função de pobreza. A adição do componente de desigualdade revela que, em princípio, políticas que busquem uma melhora na distribuição da renda são mais efetivas no combate à pobreza do que aquelas que objetivam unicamente o aumento do nível de renda.

Em síntese observa-se que, tanto para 2000 quanto para 2010, o índice de desigualdade apresentou tendência inversa com a elasticidade-desigualdade da pobreza positiva, ou seja, um aumento na desigualdade de renda eleva a incidência de pobreza local. Com relação ao sinal dos coeficientes, todos foram coerentes com a teoria econômica. O sinal negativo dos coeficientes da renda (IDH-R), que representa a elasticidade-renda da pobreza, indicou que um acréscimo na renda leva a uma redução na pobreza multidimensional, enquanto o sinal positivo da elasticidade-desigualdade da pobreza mostra que um aumento da desigualdade resulta também em um aumento na pobreza multidimensional.

Adicionalmente, em 2010, o modelo econométrico com defasagem espacial apresentou um elevado poder de explicação (Spatial-Pseudo $\mathrm{R}^{2}=0.99$ ) para dados em cross-section, teste que serve para comparação e avaliação da robustez dos modelos. Para além disso, os modelos incorporaram corretamente a dependência espacial, ou seja, toda a autocorrelação espacial foi incorporada corretamente nos modelos, resultado indicado pelo teste de Anselin-Kelejian, que apresentou $p$-valor $>0,05 \%$. Ou seja, nesse caso não se rejeita a hipótese nula. 
Destarte, considerando a análise dos resultados, responde-se à problemática da pesquisa: dentre as variáveis consideradas no modelo, qual tem maior peso para determinar a pobreza nos bairros de Salvador? Em ordem decrescente de sensibilidade, tem-se que a porcentagem de pobres foi mais sensível às variações na Saúde, que esteve ligada às variáveis "ln (S)" e "ln (L)" como as duas variáveis de maior peso; em terceiro, tem-se a variável desigualdade de renda, representada por "ln (T)"; e em quarto lugar, a variável educação, representada pala variável "In (E)". Ou seja, políticas públicas de melhoria das condições de saúde da população dos bairros e de redução da desigualdade têm incidência direta no combate à pobreza. Resultado semelhante foi encontrado por Da Silva et al. (2009), ao relacionarem a pobreza brasileira de 1995 a 2004 com as variáveis do índice de Gini taxa de analfabetismo e renda, em ordem decrescente de sensibilidade.

Concluindo, este estudo é relevante para a reformulação de políticas públicas voltadas para o alívio e o combate à pobreza, pois permitiu enfoque maior sobre a sensibilidade regional ao englobar os 163 bairros de Salvador e constatou que investimentos em saúde e infraestrutura podem permitir: redução da pobreza multidimensional, queda expressiva na porcentagem de pobres, melhoria na oportunidade e qualidade de vida, bem como transferência mais robusta de renda. Nesse contexto, destaca-se que os policy makers devem intensificar a alocação de recursos nos programas de saúde e bem-estar e tornar mais eficiente a distribuição de renda para os mais pobres de modo a reduzir ainda mais a mortalidade infantil e a disparidade entre ricos e pobres.

\section{CONSIDERAÇÕES FINAIS}

Entendendo que os determinantes da pobreza nos bairros de Salvador estão ligados ao tipo de inserção do país na economia mundial e às raízes históricas e culturais da sociedade brasileira, este estudo investigou os fatores socioeconômicos apontados na literatura como aqueles que mais diretamente restringem as necessidades básicas dos indivíduos. Tais fatores se relacionam à desigualdade, que, por sua vez, condiciona de modo fundamental as situações de carência. Como a necessidade de reduzir a pobreza representa hoje um consenso nos meios acadêmicos, governamentais e sociais, inclusive na comunidade internacional, justificam-se os estudos que forneçam uma melhor compreensão do fenômeno. Em termos mais específicos, a grave situação de pobreza em que vive uma parcela significativa da população no Brasil, particularmente em Salvador, requer estudos que ofereçam substratos para intervenções sociais 
e governamentais. Enquanto, por um lado, são necessárias medidas focalizadas para aliviar as situações emergenciais de carência da população, por outro lado, é ainda mais relevante implementar reformas estruturais de médio e longo prazos. Nesse sentido, este trabalho contribui para os esforços de analisar a pobreza em Salvador, oferecendo elementos adicionais para uma compreensão "espacial" desse processo social, em que fatores socioeconômicos se articulam entre si e influem, de modo conjugado, sobre a tendência de um indivíduo viver em condições de pobreza.

A originalidade da abordagem aqui proposta reside tanto na aplicação desse instrumento inovador de pesquisa quantitativa de análise espacial, quanto na avaliação do seu potencial para a abordagem relacional no estudo de clusters, enquanto reflete criticamente sobre os limites dos métodos tradicionais. Deve-se ressaltar, por fim, que o presente estudo não tem a pretensão de propor uma análise sociológico-filosófica aprofundada do fenômeno da pobreza, mas de contribuir para o avanço no uso de métodos quantitativos na área.

Dessa maneira, o enfoque recaiu sobre os modos de mensuração e operacionalização empírica dos conceitos de pobreza. De modo geral, os modelos espaciais aqui construídos se revelaram como boas representações do fenômeno estudado. Isso se depreende, em primeiro lugar, dos seus coeficientes de ajuste, que indicaram os elevados níveis de coincidência entre as relações postuladas nos modelos e aquelas encontradas entre as variáveis empíricas que participaram do estudo. A qualidade dos modelos especiais se deduz, em segundo lugar, das altas capacidades explicativas da variável dependente "pobreza multidimensional". Com isso, foi possível afirmar que os fatores incluídos nas modelagens, de fato, atuam de forma relevante para determinar a pobreza das famílias pobres de Salvador, o que não quer dizer serem eles as "causas" da pobreza. Simplesmente, suas manifestações influenciam a pobreza multidimensional de maneira significativa, no caso da camada da população levada em conta. Mais um elemento que contribuiu para a grande capacidade explicativa dos modelos foi a relativa heterogeneidade da população-alvo, definida como aquelas pessoas que vivem abaixo da linha de pobreza.

Quanto aos coeficientes produzidos por esse método, pôde-se perceber que as relações estabelecidas entre as variáveis tiveram suas intensidades estimadas, de modo a permitir detectar os fatores de maior influência sobre as condições de vida das pessoas pobres em Salvador. Sob o ponto de vista da formulação de políticas, a informação relevante é aquela a apontar quais fatores mais influenciam as condições de pobreza. Os resultados fornecidos pela econometria espacial possibilitam identificar alguns fatores que explicam uma parcela 
significativa do fenômeno, dentre os quais se podem citar: o nível de analfabetismo, a mortalidade infantil até cinco anos e a concentração de renda, todos esses três de influência positiva, ao lado da renda média e da longevidade, cuja influência foi negativa. Além disso, o erro espacial mostrou-se relevante, de modo que o impacto da pobreza foi correlacionado espacialmente com os resíduos, como variável explicativa do modelo.

Como se pode observar, os fatores relevantes supracitados são críticos para compreender o fenômeno da pobreza e para desenvolver ações que visem à melhoria das condições de vida das pessoas atingidas. Por isso, eles merecem receber um acompanhamento mais pormenorizado do que aquele talvez propiciado por métodos quantitativos tradicionais. Assim, como uma das principais recomendações deste estudo, sugere-se realizar estudos que acompanhem as condições de vida dos bairros pobres ao longo de vários anos. Tais estudos longitudinais, calcados na econometria espacial, método que funciona como "radiografia" de determinado processo social e de suas relações estruturais, permitiriam contemplar a evolução dos fatores dentro de uma abordagem relacional. Com isso, seria possível verificar os impactos das políticas sobre a dinâmica das associações entre todas as variáveis implicadas.

Os resultados podem colaborar para reformular políticas públicas, na medida em que permitem identificar necessidades prioritárias. Por exemplo, apontam para a otimização dos gastos públicos, que devem privilegiar políticas envolvendo a criação de postos de saúde, a ampliação do comércio local para fins de geração de renda, a melhoria da educação com políticas específicas contra o analfabetismo nas localidades mais pobres, bem como investimentos em infraestrutura e saneamento básico. Indicam ainda que políticas públicas voltadas à distribuição mais igualitária da renda são mais efetivas para reduzir a pobreza do que aquelas buscando unicamente aumentar a renda.

Verificou-se também que as duas abordagens, multidimensional e unidimensional, não descrevem o mesmo cenário de pobreza, porque existem, de fato, mudanças significativas na configuração dos mais e menos pobres quando incluídas outras variáveis não econômicas. Em outras palavras, a análise dos indicadores para bairros de Salvador constatou que as localidades podem ocupar posições bastante distintas, podendo em alguns casos uma região considerada a menos pobre, de acordo com certa metodologia, passar a fazer parte da metade mais pobre em outra, principalmente quando analisados grandes períodos. Nessa lógica, é possível inferir a maior eficiência da análise multidimensional, capaz de gerar novos horizontes acerca do que se conhece por pobreza. Como limitação da pesquisa, pode-se apontar a falta de dados referentes ao acesso a serviços de segurança, de esporte, de lazer e de cultura, dentre outros. 
Por fim, a agenda de pesquisa futura contempla a inclusão de novas dimensões da pobreza, bem como uma análise temporal. Acredita-se que futuros estudos da pobreza precisam considerar outros detalhes como o contexto econômico local e regional, pois é nos estratos sociais mais baixos que as mazelas sociais reverberam com maior força. 


\section{REFERÊNCIAS}

ADAMS, R. J. Economic Growth, Inequality, and Poverty: Findings from a New Dataset. World Bank Policy Research Working Paper n. 2972, Washington, DC, 2002.

ALKIRE, S.; FOSTER, J. Counting and Multidimensional Poverty Measurement. OPHI Working paper, v. 7, 2009.

ALLARDT, E. Having, loving, being: An alternative to the Swedish model of welfare research. The quality of life, v. 8, p. 88-95, 1993.

ALMEIDA, E. Econometria espacial. Campinas-SP: Alínea, 2012.

PEROBELLI, F. S.; FERREIRA, P. G. C. Existe convergência espacial da produtividade agrícola no Brasil? Revista de Economia e Sociologia Rural, v. 46, n. 1, p. 31$52,2008$.

AMARAL, R. F. do; CAMPOS, K. C.; LIMA, P. V. P. S. Distribuição da pobreza no estado do Ceará: uma abordagem multidimensional. Interações, v. 16, n. 2, p. 327-337, 2016.

ANAND, S.; SEN, A. Concepts or Human Development and Poverty! A Multidimensional Perspective. United Nations Development Programme, Poverty and human development: Human development papers, p. 1-20, 1997.

ANSELIN, L. Spatial Econometrics: methods and models. Kluwert Academic, 1988.

Spacestat tutorial: a workbook for using Spacestat in the analysis of spatial data. Illinois: Urbana, 1992.

; BERA, A. K. Spatial dependence in linear regression models with an introduction to spatial econometrics. Statistics Textbooks and Monographs, v. 155, p. 237-290, 1998.

ASSELIN, Louis-Marie. Composite Indicator of Multidimensional Poverty. CECI, 2002.

ARAÚJO, J. A.; MORAES, G. S.; CRUZ, M. S. Estudo da pobreza multidimensional no Estado do Ceará. Sobral: Laboratório de Estudos Regionais. (Texto para discussão 03), 2012. 
ÁVILA, J. F. Pobreza no Rio Grande do Sul: uma análise exploratória da sua distribuição espacial a partir de indicadores multi e unidimensionais. (Dissertação de Mestrado em Economia do Desenvolvimento). Porto Alegre: FACE, PUCRS, 2013.

BAUMONT, C. Spatial effects in housing price models: do housing prices capitalize urban development policies in the agglomeration of Dijon (1999)? Technical report, Université de Bourgogne, Pôle d'Economie et de Gestion, 2004.

BIBI, S. Measuring poverty in a multidimensional perspective: A review of literature. PMMA Working Paper, 2005.

BOSSERT, W.; CHAKRAVARTY, S. R.; D’AMBROSIO, C. Multidimensional poverty and material deprivation. Montreal. CIREQ-Cahier, 2009.

BOURGUIGNON, F.; CHAKRAVARTY, S. R. Multidimensional poverty orderings. Delta, 2002.

The measurement of multidimensional poverty. Journal of Economic inequality, v. 1, n. 1, p. 25-49, 2003.

CARVAlHO, I. M. M.; PEREIRA, G. C. Segregação socioespacial e desigualdade em Salvador. Cadernos do CEAS - Revista Critica de Humanidades, v. 235, p. 5-22, 2015.

CUMMINS, R. A. The domains of life satisfaction: An attempt to order chaos. Social indicators research, v. 38, n. 3, 303-328, 1996.

DA SILVA, D. O. P.; DE ARAÚJO JUNIOR, I. T.; DA SILVA, M. V. B. Pobreza, desigualdade e crescimento: evidências obtidas a partir de painel dinâmico para os estados brasileiros. Revista Brasileira de Estudos Regionais e Urbanos, v. 3, n. 2, p. 1-26, 2009.

DUCLOS, J. Y.; SAHN, D. E.; YOUNGER, S. D. Robust multidimensional poverty comparisons. The economic journal, v. 116, n. 514, p. 943-968, 2006.

ESPÓSITO, L.; CHIAPPERO-MARTINETTI, E. Multidimensional Poverty Measurement: Restricted and Unrestricted Hierarchy of Weights Among Poverty Dimensions. OPHI Working Papers, v 22, 2008. 
FLORAX, R. J.; FOLMER, H.; REY, S. J. Specification searches in spatial econometrics: the relevance of Hendry's methodology. Regional Science and Urban Economics, v. 33, n. 5, p. 557-579, 2003.

FOSTER, J. The Foster-Greer-Thorbecke poverty measures: Twenty-five years later. Institute for International Economic Policy Working Paper Series. Elliott School of International Affairs. The George Washington University. Washington DC, 2010.

; GREER, J.; THORBECKE, E. A class of decomposable poverty measures. Econometrica: journal of the econometric society, p. 761-766, 1984.

FOSTER, J.; SHORROCKS, A. F. Poverty orderings. Econometrica: Journal of the Econometric Society, p. 173-177, 1988a.

Poverty orderings and welfare dominance. In: Distributive Justice and Inequality (p. 91-110). Springer, Berlin, Heidelberg, 1988 b.

GIOVANETTI, A. E.; RAIHER, A. P. Uma Análise Multidimensional da Pobreza dos Municípios Paranaenses em 2010. Revista de Estudos Sociais, v. 17, n. 33, p. 228-248, 2015.

HOFFMANN, R. Transferências de renda e a redução da desigualdade no Brasil e em cinco regiões entre 1997 e 2004. Revista Econômica, v. 8, n. 1, p. 85-81, 2006.

Elasticidade da Pobreza em Relação à Renda Média e à Desigualdade no Brasil e nas Unidades da Federação. Revista Economia, v. 6, n. 2, p. 255-289, 2005.

KAGEYAMA, A.; HOFFMANN, R. Pobreza no Brasil: uma perspectiva multidimensional. Economia e Sociedade, v. 15, n. 1, p. 79-112, 2006.

Pobreza rural no Brasil em 2003. In: Encontro de Nacional de Economia Política. Campinas, SP: Sociedade Brasileira de Economia Política, 2005.

KAKWANI, N.; SILBER, J. (Eds.). Quantitative approaches to multidimensional poverty measurement. Springer, 2008.

KRISHNAKUMAR, J. Going beyond functionings to capabilities: an econometric model to explain and estimate capabilities. International Conference on The Many Dimensions of Poverty International Poverty Centre, 2005. 
LACERDA, F. C. C. A pobreza na Bahia sob o prisma multidimensional: uma análise baseada na abordagem das necessidades básicas e na abordagem das capacitações. (Dissertação de Mestrado em Economia). UFU, Uberlândia, Brasil, 2009.

LIMA, A. L. M. C. Modelagem de Equações Estruturais: uma Contribuição Metodológica para o Estudo da Pobreza. Tese (Doutorado em Ciências Sociais) - Universidade Federal da Bahia, Salvador, Brasil, 2005. 297p.

MARANDUBA JÚNIOR, N. G.; ALMEIDA, E. S. D. Spatial convergence analysis of tax transfers from the Robin Hood Act. Economia e Sociedade, v. 18, n. 3, p. 583-601, 2009.

NEDER, H. D.; SILVA, J. L. M. D. Pobreza e distribuição de renda em áreas rurais: uma abordagem de inferência. Revista de Economia e Sociologia Rural, v 42, n. 3, p. 469-486, 2004.

OLIVEIRA, R. C. D.; ALMEIDA, E.; FREGUGliA, R. D. S.; BARRETO, R. C. S. Desmatamento e crescimento econômico no Brasil: uma análise da curva de Kuznets ambiental para a Amazônia legal. Revista de economia e sociologia rural, v. 49, n. 3, p. 709-739, 2011.

PECI, A.; NERI, M. Políticas públicas de combate à pobreza. Revista de Administração Pública, v. 51, n. 2, 2017.

PINTO, M. S.; OLIVEIRA, J. C. Crescimento pró-pobre: Análise dos estados brasileiros entre 1995 e 2007. Revista de Economia Contemporânea, v. 14, n. 2, p. 327-358, 2010.

PNUD (Programa das Nações Unidas para o Desenvolvimento). Atlas do Desenvolvimento Humano nas Regiões Metropolitanas Brasileiras. 2014. Disponível em: <http://atlasbrasil.org.br/2013/pt/download/>. Acesso em: jul. 2017.

Poverty in the human development perspective: concept and measurement. In: development. Report, 1997.

REY, S. J.; MONTOURI, B. D. US regional income convergence: a spatial econometric perspective. Regional studies, v. 33, n. 2, p. 143-156, 1999.

ROTHWELL, J.; MASSEY, D. Geographic effects on intergenerational income mobility. Economic Geography, v. 91, n. 1, p. 83-106, 2015.

ROCHA, S. Impacto sobre a pobreza dos novos programas federais de transferência de renda. 
Revista de Economia Contemporânea, v. 9, n. 1, p. 153-185, 2005.

SANTOS, E. I. dos; CARVALHO, Í. C. S. dos; BARRETO, R. C. S. Pobreza multidimensional no estado da Bahia: uma análise espacial a partir dos censos de 2000 e 2010. Revista de Administração Pública, v. 51, n. 2, p. 240-263. São Paulo, 2017.

SANTOS, M. E. Measuring multidimensional poverty in Latin America: Previous experience and the way forward. OPHI Working Papers, v. 66, 2014.

SEN, A. K. Desenvolvimento Como liberdade. Trad. Laura Teixeira Mota. Rev. tec. Ricardo Doniselli Mendes. 6. São Paulo: Companhia das Letras, 2000.

Development as Freedom. Oxford: Oxford University Press, 1999.

The concept of development. In: CHENERY, H., SRINIVASAN, T. N. (Eds.). Handbook of development economics. Amsterdã. Elsevier Science. 1. 9-26. 1988

SILVA, M. C. P.; BARROS, R. P. Pobreza multidimensional no Brasil. In: ENCONTRO NACIONAL DE ECONOMIA, 2006, p. 1-20. Anais da Anpec. Salvador, 2006.

STIGLITZ, J. E.; SEN, A.; FITOUSSI, J. P. Report by the commission on the measurement of economic performance and social progress. Paris: Commission on the Measurement of Economic Performance and Social Progress, 2009.

TAQUES, F. H.; OLIVEIRA, J. C. T. Existe uma relação entre nível de renda, desigualdade e pobreza? Um estudo a partir de elasticidades. Economia e Desenvolvimento, Santa Maria RS, v. 26, n. 2, p. 21-42, 2014.

TSUI, K. Y. Multidimensional poverty indices. Social Choice and Welfare, v. 19, p. 69-93, 2002.

URA, K.; ALKIRE, S.; ZANGMO, T.; WANGDI, K. A short guide to gross national happiness index. The Centre for Bhutan Studies. 1-96, 2012. 